Federal Reserve Bank of Minneapolis Research Department

\title{
The Stolper-Samuelson Effects of a Decline in Aggregate Consumption*
}

\author{
Erzo G. J. Luttmer \\ Working Paper 703
}

February 2013

\begin{abstract}
Consider an economy in which various types of labor are used to produce consumption, but not all types of labor are useful for upgrading the stock of organization capital-that is, for replacing old projects with more productive new projects. When news induces consumers to want to save more, low-quality projects are destroyed across all sectors of the economy, even though the economy is set to increase its stock of new projects. Labor that can be used to create new projects becomes more expensive and labor that cannot becomes cheap. Average wages may not change at all, and the employment of workers who cannot invest in new projects will decline. If physical capital complements the inputs of these workers, investment in physical capital tends to move together with their employment. These results are derived analytically for a prototype economy that has the essential ingredients of empirically relevant equilibrium models of firm heterogeneity.
\end{abstract}

Keywords: Bayesian updating; Aggregate consumption; Factor prices JEL classification: E25, E32, L16

*Luttmer: University of Minnesota and Federal Reserve Bank of Minneapolis. Comments and suggestions welcome. I thank Matthew E. Kahn for helpful comments on an earlier version. The views expressed herein are those of the author and not necessarily those of the Federal Reserve Bank of Minneapolis or the Federal Reserve System. 


\section{INTRODUCTION}

Consider an economy with consumers who believe that there is a positive probability that the income generated by some of their assets will rise significantly at some uncertain future date. But they cannot suppress the nagging feeling that the probability that this will never happen is also positive. Furthermore, they know that in that event they will eventually receive a negative signal confirming that no rise in income will be forthcoming. That is, there is a signal that can "prove a negative." If, conditional on no eventual rise in income, the probability of an early arrival of the negative signal is high enough, then a long period without a negative signal will make consumers believe, with a very high degree of confidence, that they will eventually receive the rise in income. ${ }^{1}$ They consume accordingly. When an economy has been in this state for some time, what exactly will happen if the negative signal does eventually arrive?

In an economy with a Cass-Koopmans technology and standard preferences over consumption and leisure, consumption drops and employment rises, as the economy begins to accumulate more capital. The increased employment lowers the marginal product of labor and thus wages. Consumption certainly did drop sharply during the 2008-2009 recession: the 10\% drop in nominal non-durable consumption from 2008Q3 to 2009Q1 was unprecedented in postwar US data. But employment fell by more than $4 \%$ over the same period, and the employment cost index for private industry workers rose.

This paper gives an analytical exposition of the effect of sudden belief revisions on job creation and destruction in an economy in which jobs are a form of capital, and not all employees have the ability to create new jobs. Managers can use their time to create new projects, or they can operate existing new and old projects to produce consumption goods. Consumption goods are produced in teams that consist of both managers and workers. Thus the technology for creating new projects is intensive in the managerial input and the technology for producing consumption goods is labor intensive. When consumers realize they are not as wealthy as they thought they were, they reduce consumption and save more. This lowers the real interest rate, making the development of new projects more profitable. The price of new projects rises relative to the price of consumption. The Stolper-Samuelson theorem therefore implies an increase in managerial wages, and a decline in worker wages. If the economy operates in a region where the supply of worker labor is sufficiently elastic, this can lead to a significant reduction

\footnotetext{
${ }^{1}$ By Bayes' rule. See equation (3) below.
} 
in the employment of workers, while managers are reallocated towards developing new projects.

The reduction in worker employment means fewer active projects. At the same time, new projects are being created, at an increased pace because managers have been reallocated away from operating existing projects. New project creation and an endogenous destruction of old projects can only happen at the same time if these projects are different - the value of new projects must be positive and the value of projects that are abandoned must be zero. ${ }^{2}$ As in models of vintage capital or firm entry and exit, new projects are assumed to be more productive than old projects. New projects become old randomly, and then remain in that state forever. Over time, this generates a large supply of marginal projects with equilibrium revenues that are merely covering the cost of the managers and workers it takes to operate them. Unlike new projects, these projects do not generate profits and do not become more valuable when interest rates fall. Scrapping some of these projects accommodates the decline in consumption that happens when consumers want to save more.

Because the negative wealth shock causes managerial wages to rise and worker wages to fall, there is no presumption that indices of the economy-wide cost of employment will be significantly affected by the revision of consumer beliefs. In fact, for the Leontief technology that will be used in this paper, average employee wages do not change at all. The effect on the wages of individual employees depends very much on their skills. What matters is the extent to which employees are able to supply the factor of production used intensively in producing new projects. Given that many jobs involve a range of tasks, the consequences of a recession for the wages of some employees can be dire while others do well, although they may be hard to distinguish observationally.

Suggestive evidence comes from the incidence of unemployment in populations with different levels of educational attainment, shown in Figure 1. During the 2008-2009 recession, the unemployment rate among employees without a high school degree rose from about $8 \%$ to as much as $16 \%$, while for college graduates the rise was from $2 \%$ to only about $4.5 \%$. The BLS also reports that in 2011, the unemployment rates among holders of master's, professional and doctoral degrees were as low as 3.6\%, $2.4 \%$ and $2.5 \%$, respectively, while the overall unemployment rate among persons of age 25 and over was as high as $7.6 \%$. The second panel in Figure 1 shows employment levels for the main educational attainment indicators relative to their January 2008 levels.

\footnotetext{
${ }^{2}$ In Rogerson [2005] displaced older workers leave the labor force even as young workers enter, because they can learn on the job.
} 
Employment among the college educated was essentially flat during the recession, while the number of employed adults with no completed high school education fell by more than $10 \%$. These patterns are precisely what the model in this paper predicts if the factor of production involved in creating new projects is more widely distributed among college graduates than among adults with less than a high school education. ${ }^{3}$
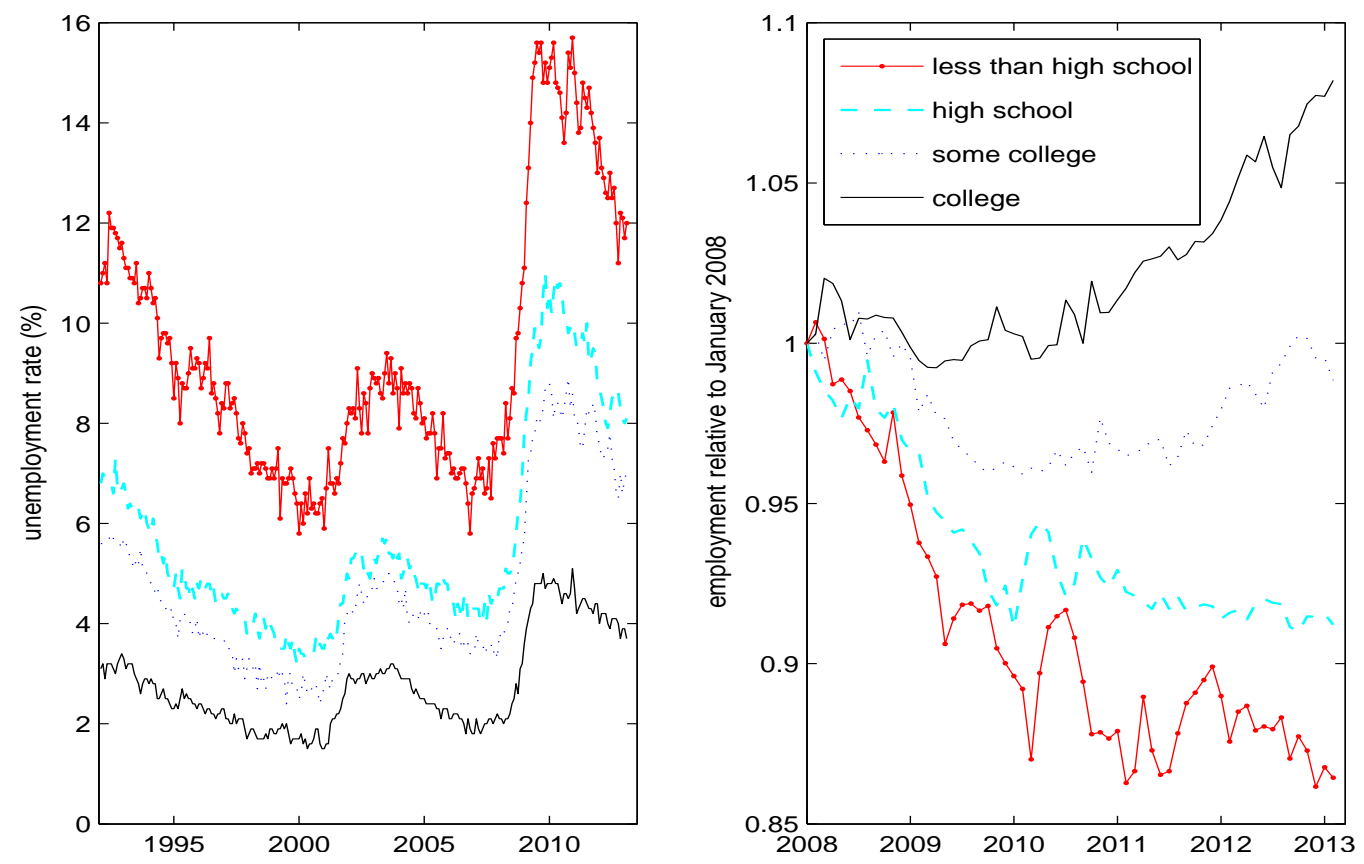

Figure 1 Unemployment Rate and Employment by Educational Attainment

A common critique of models of aggregate employment fluctuations that appeal to sectoral shocks and reallocation of labor is that, in fact, employment in a typical recession is down across many if not most sectors of the economy. The typical recession does not look like a sudden shift of demand away from one sector of the economy to another. But if every sector of the economy has productive and not-so-productive projects, such an economy-wide decline in employment is to be expected when there is a shock that reduces consumer wealth. This is not to say that employment will be affected equally across different sectors of the economy. As is well known, employment reductions in

\footnotetext{
${ }^{3}$ The data are from the Current Population Survey compiled by the U.S. Bureau of Labor Statistics. The second panel in Figure 1 also reflects a steady increase in the number of college graduates. Educational attainment can only be viewed as a proxy for the ability to create new projects. For example, creating new projects often also requires experience that recent college graduates lack, the history of Microsoft and Google notwithstanding.
} 
declining sectors tend to be concentrated in recessions. ${ }^{4}$ The changes in employment in the manufacturing and health care sectors of the U.S. economy during the 20082009 recession were very different. To the extent that old projects are more prevalent in declining than in growing sectors of the economy, the destruction of old projects triggered by a sudden desire of consumers to save will generate larger reductions in employment in the former than in the latter. ${ }^{5}$

Related Literature The economy described in this paper is designed to give an analytical account of phenomena that occur more generally in economies with heterogeneous producers subject to idiosyncratic productivity shocks. Models with heterogeneous producers are central in modern theories of international trade (Eaton and Kortum [2003], Melitz [2005]). Models with idiosyncratic productivity dynamics and entry and exit have been used to understand aggregate productivity growth and the size distribution of firms (Luttmer [2007, 2011a]). Barriers to reallocation of resources are potentially important in explaining aggregate productivity differences across countries (Restuccia and Rogerson [2008] and Hsieh and Klenow [2009]). The current paper reduces the idiosyncratic productivity dynamics to a bare minimum: there are productive new projects that eventually depreciate to less productive old projects. Because the factor of production used to create new projects can also be used to produce consumption, the structure of the resulting model is reminiscent of the two-sector growth models of Uzawa [1965] and Lucas [1988]. But here improvements in project quality are not cumulative and the economy does not grow. ${ }^{6}$ This makes it easier to focus on the transitory dynamics that arise when Bayesian updating gets off track temporarily.

The costly reallocation of labor resulting from shocks at the firm, industry, and aggregate level has a long tradition as a candidate explanation for employment fluctuations over the business cycle. Building on Lucas and Prescott [1974], Lillien [1982] considers the consequences of fluctuations in the variance of sectoral shocks. Alternatively, Caballero and Hammour [1996] rely on aggregate productivity shocks to drive the cycli-

\footnotetext{
${ }^{4}$ See Blanchard and Diamond [1990] and Davis, Haltiwanger and Schuh [1996] for evidence up to 1988. Jaimovich and Siu [2012] present more recent evidence and document the incidence of employment declines across occupations. They attribute jobless recoveries to a secular decline in routine occupations that is concentrated in recessions.

${ }^{5}$ Lower interest rates make the future income generated by a project more important. Marginally profitable projects with a negative scrap value (termination costs, any violation of free disposal) can decline in value when interest rates fall. This is a additional channel by which a decline in aggregate consumption can accelerate the scrapping of projects in declining industries.

${ }^{6}$ See Luttmer [2012a] for a growth model with Leontief technologies similar to the ones used here.
} 
cal pattern of reallocation: when productivity is low, it is a good time to reallocate resources. ${ }^{7,8}$ In the current paper, aggregate productivity shocks or changes in their dispersion across sectors play no role. The technology for producing consumption is as good as ever, and there is also no change in the technology for creating new projects. But the factor intensities of these technologies are different. The increase in the price of new projects relative to consumption goods that is inevitable when consumers want to save more has Stolper-Samuelson implications for the factor prices of different types of labor and their equilibrium supplies. Frictions in the labor market are assumed away only for simplicity.

Early quantitative attempts to model news shocks appear in Cochrane [1994] and Danthine, Donaldson and Johnson [1998]. Beaudry and Portier [2004] describe an economy with durable and non-durable consumption goods in which optimistic beliefs about future productivity give rise to high consumption, investment, and employment. Consumption and investment collapse when it is realized that productivity is not going to be as high as anticipated. Jaimovich and Rebelo [2009] obtain the same co-movement between consumption and investment but use an alternative preference specification to weaken the tendency of wealth effects to make households work more when bad news happens. The baseline specification in this paper has standard preferences and only intangible investment: the creation of new projects. Optimistic consumer wealth perceptions draw managerial resources away from investing in new projects and workers into the labor force in order to produce more consumption with a stock of projects that is not being upgraded as much as before because managers are busy producing consumption. Negative news then reverses this. Consumption and worker employment co-move because there is no other way to vary consumption in the short run, unlike what happens in the basic Cass-Koopmans economy. On the other hand, consumption and investment in new projects move in opposite directions. A natural extension of the baseline specification is to assume that teams of managers and workers also need equipment and structures to produce consumption. Investment in these types of capital

\footnotetext{
${ }^{7}$ Caballero and Hammour [1996] emphasize that the amount of realloction may not be efficient when there are contractual imperfections. In Barlevy [2002], the fact that workers can search on the job actually makes recessions a bad time to improve the distribution of match quality in the economy.

${ }^{8}$ Sketching elements of a model of organization capital similar to that described here, Hall [1991] is agnostic about the source of shocks. Cooper and Haltiwanger [1993] use aggregate taste and technology shocks. Caballero and Hammour [1994] consider demand shocks in a model of industry equilibrium similar to Hopenhayn [1992]. Aghion and Saint-Paul [1998] describe a small open economy subject to world demand shocks.
} 
will then tend to co-move with consumption and worker employment, as observed in the data. $^{9}$

The belief shock that is the focus of this paper is one that affects the perceived level of wealth of consumers, and not one that affects growth rates. The effects of changes in perceived growth rates are important in models of long-run risk (Bansal and Yaron [2004]), and they can be large because small changes in growth rates have large effects on present values. But direction of these effects depends crucially on whether the intertemporal elasticity of substitution of the representative household is larger or smaller than one. The level effects in this paper operate with an intertemporal elasticity of substitution equal to one.

Section 2 describes the economy with team production. The equilibrium is studied in Section 3. Section 4 describes three extensions that are likely to be important in any quantitative implementation: (i) irreversibilities, (ii) fixed investment, and (iii) a modified technology for producing new projects that not only uses managers but also builds on existing projects. Section 5 concludes.

\section{TeAm Production}

The economy is one with enough markets to justify the use of a representative household. This representative household has preferences over consumption $C_{t}$ and labor $L_{t}$ given by

$$
\mathrm{E}_{0}\left[\int_{0}^{\infty} e^{-\rho t}\left\{\ln \left(C_{t}\right)-\frac{\xi L_{t}^{1+1 / \varepsilon}}{1+1 / \varepsilon}\right\} \mathrm{d} t\right],
$$

where $\rho, \xi$ and $\varepsilon$ are all positive. Besides workers who supply labor, the representative household also has managers who inelastically supply $H$ units of a managerial factor of production. Thus $\varepsilon$ is the Frisch elasticity of the labor supply of workers, not of all employees in this economy.

A natural interpretation of $(1)$ is that employees are heterogeneous in terms of their endowments $h$ of the managerial input, which aggregate to $H$. Employees with $h=0$ only supply labor, but employees with $h>0$ supply both labor and the managerial input. Employees with high values of $h$ will tend to have high levels of consumption

\footnotetext{
${ }^{9}$ This is only a sampling of the literature on news and aggregate demand shocks. Recent contributions include Bai, Rios-Rull and Storesletten [2012], Den Haan and Kaltenbrunner [2009], Schmitt-Grohé and Uribe [2012], and Ilut and Schneider [2012]. In the Lucas [1972] tradition, Angeletos and La'O [2012] and Lorenzoni [2009] decribe models in which information is dispersed and agents also learn from prices.
} 
and choose to supply very little labor. Their compensation is determined mostly by the managerial input they supply inelastically. Employees with $h=0$ are only paid for their labor. In this interpretation, the preference parameter $\xi$ depends on the Pareto weights assigned to the various types of consumers, and market completeness is crucial in arguing that this parameter is invariant to changes in beliefs.

Consumption Consumption goods can be produced using a combination of labor, the managerial input, and "projects." There are new and old projects. Old projects are less productive than new projects, and new projects depreciate to become old projects randomly at an average rate $\delta$. Old projects do not depreciate further and remain available forever. Given measures $N_{t}$ and $K_{t}$ of new and old projects, and given a supply of managerial inputs $M_{t} \in[0, H]$ and a worker labor supply $L_{t}$, output $Y_{t}$ of consumption goods is constrained by

$$
\begin{aligned}
Y_{t} & \leq \min \left\{N_{t}, T_{N, t}\right\}+\psi \min \left\{K_{t}, T_{K, t}\right\} \\
T_{N, t}+T_{K, t} & \leq \min \left\{L_{t}, M_{t}\right\}
\end{aligned}
$$

where $\psi \in(0,1)$. Thus managers and workers form production teams in fixed proportions, and then these teams are assigned to projects. Since $\psi$ is less than 1 , it is optimal to assign as many production teams as possible to new projects. The unit span of control of managers is a normalization that can be modified by changing the units of $M_{t}$ and $H$.

New Projects New projects can be created by managers only. Accounting for random depreciation at the rate $\delta>0$, the stock of new projects evolves subject to the constraint $\mathrm{D} N_{t} \leq-\delta N_{t}+\gamma\left(H-M_{t}\right)$, where $H-M_{t} \in[0, H]$ is the measure of managers not used to produce consumption, and $\gamma$ is a positive productivity parameter.

If new projects are continuously being created, then there will be a continuous flow of projects that become old. That is, the stock of old projects evolves subject to the constraint $\mathrm{D} K_{t} \leq \delta N_{t}$. Since old projects do not depreciate, the stock of old projects will eventually exceed the number of teams of managers and workers that can possibly be formed. This eliminates old projects as a state variable in the long run. More importantly, it means that old projects are taken out of service as a result of equilibrium decisions, and not because they depreciate exogenously. 
An Outside Source There is also an "outside source" of consumption, denoted by $y_{t}$. The aggregate resource constraint for household consumption is thus

$$
C_{t} \leq y_{t}+Y_{t}
$$

The flow $y_{t}$ of consumption can be the net output of a long-lived asset - an asset in fixed supply that can be used together with output to produce more output, up to a certain scale. One such long-lived asset could be the human capital of employees who are not active in the markets for labor or managerial services. Alternatively, $-y_{t}>0$ can be a subsistence level of consumption, or perhaps the cost of shelter and other essential services. Or $-y_{t}>0$ can represent government purchases that are essential for the economy to operate but do not directly generate utility or contribute to output. Of course, $y_{t}$ can be the sum of several such components.

Prior Beliefs Initially the outside source is $y_{t}=y_{\mathrm{L}}$, but consumers believe that there is a one-time possibility that $y_{t}$ will jump to $y_{t}=y_{\mathrm{H}}>y_{\mathrm{L}}$ for all $t \geq \tau$, where $\tau \in[0, \infty]$ is a random time. Their prior beliefs are that $\tau<\infty$ with some probability $\theta \in[0,1]$ and that the density of $\tau$ conditional on $\tau<\infty$ is $\alpha e^{-\alpha \tau}$, for some known positive parameter $\alpha$. Furthermore, consumers believe that if $\tau=\infty$ then this information will be revealed at a random time $\sigma$. Conditional on $\tau=\infty$, the density of this random time is $\beta e^{-\beta \sigma}$, where $\beta$ is a known positive parameter. On the other hand, if $\tau<\infty$ then $\sigma=\infty$. The following table summarizes these prior beliefs.

\begin{tabular}{cr}
\hline event & prior belief \\
\hline$\tau \leq T, \sigma=\infty$ & $\theta\left(1-e^{-\alpha T}\right)$ \\
$\tau=\infty, \sigma \leq S$ & $(1-\theta)\left(1-e^{-\beta S}\right)$ \\
\hline
\end{tabular}

With this information structure, consider the event described by $\tau>t$ and $\sigma>t$. That is, there has been no increase in the outside source of consumption, and no explicit signal that such an increase will never happen. Given this event, the posterior probability that $\tau<\infty$ is

$$
\theta_{t}=\operatorname{Pr}[\tau<\infty \mid \tau>t, \sigma>t]=\frac{\theta e^{-\alpha t}}{\theta e^{-\alpha t}+(1-\theta) e^{-\beta t}}
$$

Observe that $\theta_{t}$ solves the logistic differential equation $\mathrm{D} \theta_{t}=(\beta-\alpha) \theta_{t}\left(1-\theta_{t}\right)$. The posterior beliefs $\theta_{t}$ can serve as a state variable. In the knife-edge case of $\beta=\alpha$, posterior beliefs do not budge from the prior beliefs as long as $\tau>t$ and $\sigma>t$. Although more and more evidence is coming in, the effects of the competing interpretations $\tau=\infty$ and $\sigma=\infty$ cancel out. As $t$ becomes large, the posterior probability $\theta_{t}$ converges to 0 
if $\alpha>\beta$ and to 1 if $\beta>\alpha$. In the latter case, the fact that there has been no signal confirming that $\tau=\infty$ (the dog didn't bark, so far) is more important than the fact that the increase in the outside source of consumption has not yet arrived. After a sufficiently long period of time, either all relevant uncertainty will have been resolved, or households firmly believe that an increase in the outside source of consumption is going to arrive at the rate $\alpha$, even if in fact it is the case that $\tau=\infty .{ }^{10}$

More concretely, suppose a belief has taken hold among households that the cost of government may eventually be reduced. Policy analysts are studying to see if this is possible. If not, the policy analysts are expected to find out, more quickly than the cost of government is expected to come down if a reduction in the cost of government is possible. The more time passes without the policy analysts raising a red flag, the more optimistic consumers become about the future cost of government. Their optimism vanishes when the policy analysts do reach a negative verdict. ${ }^{11}$ Households understand the tax consequences of the cost of government and experience a negative wealth shock.

The maintained assumption here is that there is only one $\tau$. One can easily imagine a steady stream of new possibilities about which consumers again and again must form beliefs, without fully-justified historical parallels to base their beliefs on. Consumers know that the world is fundamentally non-stationary. Paraphrasing the title of Reinhart and Rogoff [2009], they never ignore the possibility that this time might indeed be different. If consumers have a healthy dose of skepticism, then $\theta$ will be close to 0 . If their skepticism is justified, then $\{\tau=\infty, \sigma<\infty\}$ will be the rule, and events such as $\{\tau=\infty, \sigma>t\}$ for large $t$ will be rare, as are deep recessions. But they do occur. Bad ideas are knocked down quickly most of the time, but not always. ${ }^{12}$

\footnotetext{
${ }^{10}$ They are confident Bayesians, but not overconfident, as in Scheinkman and Xiong [2003]. The assumption $\beta>\alpha$ means that no news is good news. In Zeira [1999] no news is good news because growth rates decline at an uncertain time. See Pastor and Veronesi [2009] for a survey of the recent literature on learning in financial markets.

${ }^{11}$ One can omit the "policy" from "policy analysts" and apply this scenario to stocks that may produce earnings after some uncertain future date. At constant interest rates, the price of a stock with earnings $y_{t}$ will follow the logistic posterior (3) as long as $\tau>t$ and $\sigma>t$. For large $t$, consumers will think that the stock price has reached what looks like a permanenty high plateau, and will go even higher when $\tau<\infty$ finally arrives. But if $\tau=\infty$ then the price will crash at the random time $\sigma<\infty$. This looks like a bubble but is not, at least not in the technical sense of Santos and Woodford [1997]. Econometricians studying this economy have to worry about Peso problems.

${ }^{12}$ Barro [2006] contains evidence on the frequency and duration of economic "disasters." The learning difficulties described in this paper are only one of several possible reasons that consumption disasters can occur.
} 
A Reduced State Variable Assume the initial conditions are such that old projects are available in abundance. Because old projects do not depreciate, this will eventually be the case. There is never any reason so assign more managers to a production team than workers, or vice versa. This implies $L_{t}=M_{t}$ and thus $Y_{t} \leq \min \left\{N_{t}, L_{t}\right\}+$ $\psi \max \left\{0, L_{t}-N_{t}\right\}$. A more convenient way to write this is

$$
Y_{t} \leq(1-\psi) \min \left\{N_{t}, L_{t}\right\}+\psi L_{t} .
$$

So the marginal product of labor is 1 for $L_{t}<N_{t}$ and $\psi \in(0,1)$ for $L_{t}>N_{t}$. Throughout, the case of interest will be $L_{t}>N_{t}$, so that some old projects are in use. This implies a positive measure of marginal projects that can be abandoned when output and labor have to decline, without affecting the marginal product of labor. ${ }^{13}$ Only large reductions in employment will cause the marginal product of labor rise above $\psi$. The dynamics of the stock of new projects becomes

$$
\mathrm{D} N_{t} \leq-\delta N_{t}+\gamma\left(H-L_{t}\right), \quad L_{t} \in[0, H] .
$$

Starting from an initial stock of new projects $N_{0}$, the efficient allocation maximizes (1) subject to (2) and (4)-(5). With enough markets for contingent claims, the competitive equilibrium will be efficient.

Static Equilibrium Conditions Let $w_{t}$ be the wage of workers and $p_{t}$ the wage of managers. The price of new projects is $Q_{t}$. Since old projects are abundant, their price is zero. The marginal disutility of labor and the revenues that can be generated by managers creating new projects are outside options that set bounds on $w_{t}$ and $p_{t}$,

$$
\begin{aligned}
w_{t} & \leq \xi C_{t} L_{t}^{1 / \varepsilon}, \quad \text { w.e. if } L_{t}>0, \\
\gamma Q_{t} & \leq p_{t}, \quad \text { w.e. if } H>L_{t} .
\end{aligned}
$$

When $L_{t} \in(0, H)$ these optimality conditions determine $w_{t}$ and $p_{t}$ in terms of the outside options of workers and managers. Workers are trading off wages and the disutility of labor, and managers are trading off joining a production team or working on a new

\footnotetext{
${ }^{13}$ Models of firm heterogeneity such as Luttmer [2007] generate a large number of low-productivity firms that are close to an exit barrier, and that can be pushed across this exit barrier even by small aggregate shocks.
} 
project. The demand curve for teams of managers and workers is given by

$$
w_{t}+p_{t} \in \begin{cases}{[1, \infty),} & L_{t}=0 \\ 1, & L_{t} \in\left(0, N_{t}\right) \\ {[\psi, 1],} & L_{t}=N_{t} \\ \psi, & L_{t} \in\left(N_{t}, \infty\right)\end{cases}
$$

The marginal cost of a team of workers and managers is $w_{t}+p_{t}$, and producers compare this marginal cost with the marginal product in producing consumption. The factor income of a new project is

$$
v_{t}=\max \left\{0,1-\left(w_{t}+p_{t}\right)\right\}
$$

This will be positive if $L_{t}>N_{t}$, and possibly if $L_{t}=N_{t}$. The Lerner diagram describing the effect on managerial and worker wages of an increase in $Q_{t}$, holding fixed the price of the services of a team of managers and workers, is shown in Figure 2.

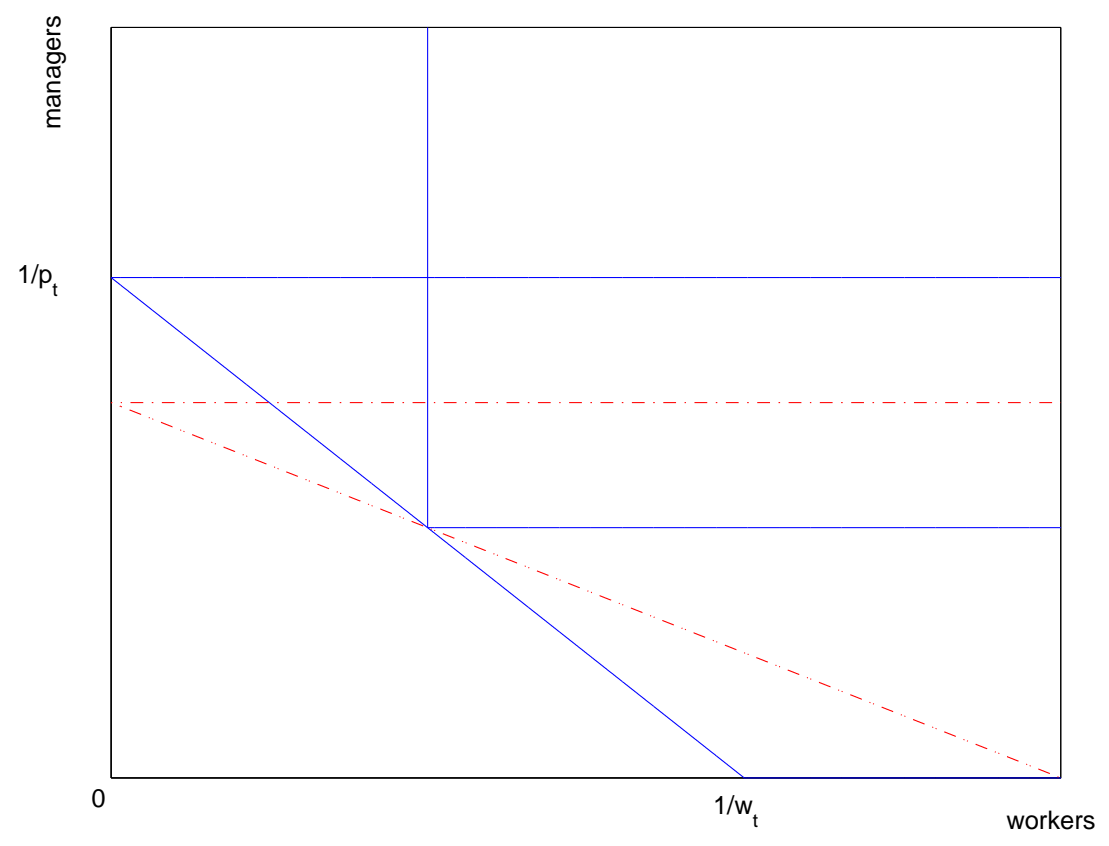

Figure 2 Managerial and Worker Wages

The strong complementarity between workers and managers can have drastic consequences for the wages of workers when managers "get busy." The cost function of the Leontief technology is simply $w_{t}+p_{t}$, and this has to be somewhere in $[\psi, 1]$ as long as production teams are used to produce consumption. As long as some old projects are in 
use, $w_{t}+p_{t}=\psi$ and the wages of managers and workers move one-for-one in opposite directions. When the managerial outside option pushes $p_{t}$ up, the wages of workers suffer. More generally, one could have labor be an input in creating new projects as well. If the technology for creating new projects is more intensive in the managerial input than the technology for producing consumption, then the Stolper-Samuelson theorem says that an increase in the price of new projects will increase the wages of managers (more than proportionally if both managers and workers are used to create new projects) and lower the wages of workers.

A Parameter Restriction When $y_{t}$ is constant at $y_{\mathrm{L}}$ or $y_{\mathrm{H}}$ for a long time, the stock of new projects $N_{t}$ will converge. The steady-state condition $\mathrm{D} N_{t}=0$ amounts to $\delta N_{t}=\gamma\left(H-L_{t}\right)$, and this implies that $N_{t}$ and $L_{t}$ vary in opposite directions across alternative steady states. If $\mathrm{D} N_{t}=0$ and $L_{t}>N_{t}$ then (2) and (4)-(5) imply

$$
C_{t}=y_{t}+(1-\psi)\left(\frac{\gamma H}{\delta}+\left(\frac{\psi}{1-\psi}-\frac{\gamma}{\delta}\right) L_{t}\right)
$$

This means that consumption $C_{t}$ and worker employment $L_{t}$ co-move across steady states with the same $y_{t}$ if and only if the following assumption holds.

\section{Assumption 1}

$$
\frac{\psi}{1-\psi}>\frac{\gamma}{\delta}
$$

This will be assumed throughout. Note that (11) says that $\psi>\gamma /(\gamma+\delta)$, so old projects must be sufficiently productive. The direct effect of more labor is more output produced using old projects. But more labor also means that more managers have to form production teams with workers. These managers are then not being used to create new projects, lowering the steady state stock of new projects and output. Assumption (11) says that the positive direct effect of worker labor supply on steady-state output dominates.

The steady state condition $\mathrm{D} N_{t}=0$ implies that $\delta N_{t}=\gamma\left(H-L_{t}\right)$, and thus that $N_{t}$ and $L_{t}$ move in opposite directions across steady states. Together with (10) and (11) this says that steady states with many new projects are steady states with low consumption - other things equal in (10). But having many new projects also lowers the amount of labor workers have to supply in a steady state. 


\section{The Competitive Equilibrium}

The ex ante economy is the economy with an outside source $y_{t}=y_{\mathrm{L}}$ that lasts while $\tau>t$ and $\sigma>t$. This economy transitions into the $y_{t}=y_{\mathrm{L}}$ ex post economy when the negative signal $\sigma$ is observed, and into the $y_{t}=y_{\mathrm{H}}$ ex post economy when $\tau$ arrives. A basic phase diagram can be used to study both the ex ante and ex post economies.

\subsection{Ex Post Economies}

Consider the ex post economy in which $y_{t}=y$ forever, for some $y \in\left\{y_{\mathrm{L}}, y_{\mathrm{H}}\right\}$. This is a deterministic economy in which the interest rate $r_{t}$ must satisfy the usual Euler condition

$$
r_{t}=\rho+\frac{\mathrm{D} C_{t}}{C_{t}} .
$$

New projects are assets that produce factor income $v_{t}$ and that depreciate to become old projects randomly at the rate $\delta$. Since old projects are free, the value of a new project drops to zero when it becomes old. The asset pricing equation for new projects is therefore

$$
r_{t} Q_{t}=v_{t}+\mathrm{D} Q_{t}-\delta Q_{t} .
$$

The required return on a project comes in the form of factor income and capital gains, with capital gains arising from changes in the value of new projects, and depreciation.

Households want to exhaust their present-value budget constraints. This implies the transversality condition

$$
\lim _{t \rightarrow \infty} e^{-\rho t} \frac{Q_{t} N_{t}}{C_{t}}=0 .
$$

Assuming $K_{0}$ is large enough, the competitive equilibrium for the ex post economy is determined by (2), (4)-(5) and (12)-(14). The equilibrium only depends on the state variable $N_{t}$. Write $C_{t}=C\left(N_{t} \mid y\right), L_{t}=L\left(N_{t} \mid y\right)$ and $Q_{t}=Q\left(N_{t} \mid y\right)$, respectively, for equilibrium consumption, labor, and the price of new projects. Two key variables in the ex ante economy will be the shadow prices $\Lambda\left(N_{t} \mid y\right)=Q\left(N_{t} \mid y\right) / C\left(N_{t} \mid y\right), y \in\left\{y_{\mathrm{L}}, y_{\mathrm{H}}\right\}$.

\subsubsection{Ex Post Steady States}

Consider steady states in which some old projects are in use. This implies that the marginal product of a team of managers and workers is $\psi$, and that the factor income of a new project is $1-\psi$. Consumption is constant and hence $r_{t}=\rho$. The asset pricing equation (13) then pins down all prices via

$$
w=\psi-p, \quad p=\gamma Q, \quad Q=\frac{1-\psi}{\rho+\delta} .
$$


The resulting worker wage equals $((\rho+\delta+\gamma) \psi-\gamma) /(\rho+\delta)$. Clearly, this requires that $\psi>\gamma /(\rho+\delta+\gamma)$, which is implied by Assumption 1 since $\rho$ is positive. Notice that an increase in $\gamma /(\rho+\delta)$ reduces the worker share of the team factor price $\psi$. The steady state supply of labor is now determined by $w=\xi C L^{1 / \varepsilon}$ and (10), which yields

$$
w=\xi\left(y+(1-\psi)\left(\frac{\gamma H}{\delta}+\left(\frac{\psi}{1-\psi}-\frac{\gamma}{\delta}\right) L\right)\right) L^{1 / \varepsilon} .
$$

Assumption 1 implies that the right-hand side is increasing in $L$. This ensures a unique solution for $L$. The steady state requires $\delta N=\gamma(H-L)$ and the assumption that some old projects are in use requires $L>N$. It follows from (15)-(16) that this condition is met if and only if Assumption 1 is augmented with the following assumption.

\section{Assumption 2}

$$
0<\xi\left(y+\frac{\gamma H}{\gamma+\delta}\right)\left(\frac{\gamma H}{\gamma+\delta}\right)^{1 / \varepsilon}<\frac{(\rho+\delta+\gamma) \psi-\gamma}{\rho+\delta}
$$

This condition holds for low $H$, but not too low if $y$ is negative. Note that $\gamma H /(\gamma+\delta)$ is the steady state number of projects that would arise if only new projects were in use. Assumption 2 says that at that number of projects, the wage associated with a marginal team product of $\psi$ is high enough to elicit a supply of labor that exceeds $\gamma H /(\gamma+\delta)$. In other words, there are not enough managers to keep all workers employed with only highly productive new projects.

The equilibrium condition (16) implies that an increase in $y$ results in an increase in steady state consumption $C$ and an decrease in worker employment. In turn, the lower value of $L$ means that more managers can be assigned to creating new projects, and this raises the steady state level of new projects. Households respond to a high $y$ partly by increasing consumption and partly by lowering worker employment. Since workers operate in teams with managers, this increases the number of managers available to create more new projects. Thus, if the outside source of income is high, there is a larger stock of high-quality capital, and less low-quality capital in use. ${ }^{14}$ In terms of the alternative interpretations of $y$, a long-lived asset producing more output, a lower

\footnotetext{
${ }^{14}$ In the corresponding Cass-Koopmans economy, with net output determined by the production function $F(K, L)-\delta K$, the steady state capital stock $K$ would be determined by $\xi(y+(F(1, l)-$ $\delta) K)(K l)^{1 / \varepsilon}=\mathrm{D}_{2} F(1, l)$, where $l=L / K$ follows from $\rho+\delta=\mathrm{D}_{1} F(1, l)$. Thus $K$ and $L$ would be decreasing in the outside source $y$.
} 
subsistence level of consumption, or a lower cost of government imply more consumption, lower employment for workers and more new projects.

More government purchases means a lower $y$. Thus the government can increase worker employment in this economy by spending more. The mechanism is clear from (16): since there is no effect on wages, government purchases crowd out consumption and this induces a positive labor supply response. ${ }^{15}$ The effect on the output of consumption goods of a permanent increase in government purchases is measured by the change in $(1-\psi) N+\psi L=(1-\psi)(\gamma H / \delta+(\psi /(1-\psi)-\gamma / \delta) L)$. By Assumption 1, the coefficient on $L$ is positive, and so output of consumption goods will also rise. The measure of new projects declines, as more managers are assigned to teams producing consumption. Government purchases are treated as an aggregate fixed cost, and so government purchases do not add to utility. The higher level of worker employment and the lower consumption therefore reduce steady state utility. This conclusion can be reversed without changing any of the observable implications of the model by assuming government purchases add utility in an additively separable way.

\subsubsection{Ex Post Equilibrium Trajectories}

Consider equilibrium trajectories along which $L_{t} \in\left(N_{t}, H\right)$ at all times. That is, some old projects are in use, and there remain enough managers to create some new projects. This implies $\psi=w_{t}+p_{t}, p_{t}=\gamma Q_{t}$, and $v_{t}=1-\psi$. Using $w_{t}=\xi C_{t} L_{t}^{1 / \varepsilon}$ and $C_{t}=$ $y+(1-\psi) N_{t}+\psi L_{t}$, the static equilibrium conditions can be summarized by

$$
L_{t}=l\left(N_{t}, Q_{t} / C_{t} \mid y\right)
$$

where $l=l(n, \lambda \mid y)$ solves

$$
\psi=(y+(1-\psi) n+\psi l)\left(\xi l^{1 / \varepsilon}+\gamma \lambda\right) .
$$

This determines $L_{t}$ as a function of the state $\left[N_{t}, Q_{t} / C_{t}\right]$. It will be useful to summarize the implications of (19).

Lemma 1 Let $l(n, \lambda \mid y)$ solve (19) and define $c(n, \lambda \mid y)=y+(1-\psi) n+\psi l(n, \lambda \mid y)$. Then $c(n, \lambda \mid y)$ is increasing in $n$ and $y$, and decreasing in $\lambda$. The function $l(n, \lambda \mid y)$ is decreasing in $n, \lambda$, and $y$.

\footnotetext{
${ }^{15}$ The same would be true in the Cass-Koopmans economy, but there the capital stock would also increase. Even simpler, if $\psi=1$ then all projects are the same and employment is determined by the static equilibrium condition $1=\xi\left(y_{t}+L_{t}\right) L_{t}^{1 / \varepsilon}$, as long as this implies $L_{t}<H$. A decline in $y_{t}$ would raise $L_{t}$ and lower $C_{t}=y_{t}+L_{t}$.
} 
The properties of $l(n, \lambda \mid y)$ are immediate from (19). The properties of $c(n, \lambda \mid y)$ follow from noting that $c=c(n, \lambda \mid y)$ solves $\psi=c\left(\xi([c-y-(1-\psi) n] / \psi)^{1 / \varepsilon}+\gamma \lambda\right)$. Other things equal, anything that raises the marginal cost of the managerial input $\gamma Q_{t} / C_{t}$ will lower consumption $C_{t}=c\left(N_{t}, Q_{t} / C_{t} \mid y\right)$ and worker employment $L_{t}=l\left(N_{t}, Q_{t} / C_{t} \mid y\right)$.

The dynamics of $N_{t}$ is determined by (5). The Euler condition (12) can be used to eliminate the interest rate from the asset pricing equation (13) to yield $(\rho+\delta) Q_{t} / C_{t}=$ $v_{t} / C_{t}+\mathrm{D}\left[Q_{t} / C_{t}\right]$. Using $v_{t} / C_{t}=(1-\psi) /\left(y+(1-\psi) N_{t}+\psi L_{t}\right)$ and (18)-(19) then gives

$$
\begin{aligned}
\mathrm{D} N_{t} & =-\delta N_{t}+\gamma\left(H-L_{t}\right), \\
\mathrm{D}\left[\frac{Q_{t}}{C_{t}}\right] & =\left(\rho+\delta-\frac{(1-\psi) \gamma}{\psi}\right) \frac{Q_{t}}{C_{t}}-\frac{(1-\psi) \xi L_{t}^{1 / \varepsilon}}{\psi}
\end{aligned}
$$

where $L_{t}=l\left(N_{t}, Q_{t} / C_{t} \mid y\right)$. The remaining equilibrium condition is the transversality condition (14). The phase diagram for this economy is shown in Figure 3 for both $y \in$ $\left\{y_{\mathrm{L}}, y_{\mathrm{H}}\right\}$, accounting for the regimes $L_{t}=N_{t}$ and $L_{t}<N_{t}$ that do not imply (18)-(19). Observe that the transversality condition (14) and (21) imply that $Q_{t} / C_{t}$ is proportional to the present value of $L_{t}^{1 / \varepsilon}$, discounted at the constant rate $\rho+\delta-(1-\psi) \gamma / \psi$, which exceeds $\rho$ because of Assumption 1. Alternatively, $\left(r_{t}+\delta\right) Q_{t}=1-\psi+\mathrm{D} Q_{t}$ means that the price of new projects is simply the price of a perpetuity with payoffs discounted at the rates $\left\{r_{s}+\delta\right\}_{s \geq t}$. The price of new projects is a function only of interest rates.

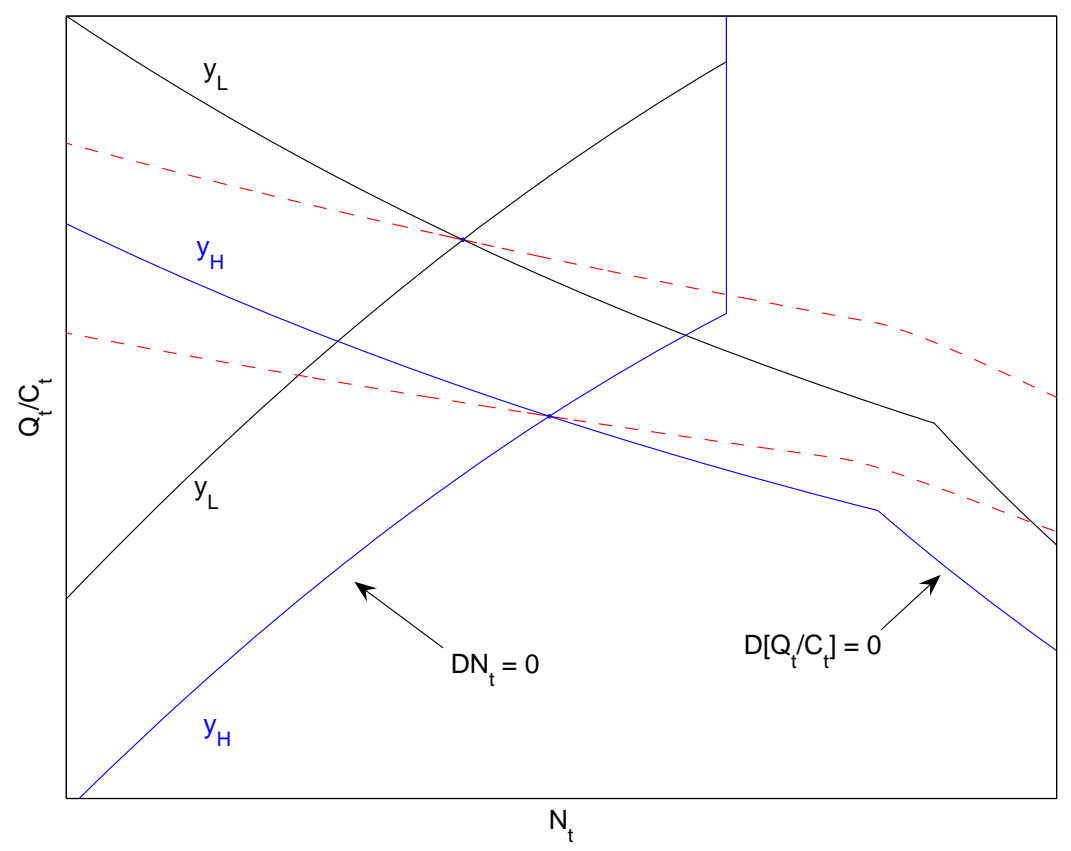

Figure 3 The Ex Post Phase Diagram 
To see that the curve $\mathrm{D} N_{t}=0$ is upward sloping, consider (19) with $n=N_{t}, \lambda=Q_{t} / C_{t}$ and use $\delta N_{t}=\gamma\left(H-L_{t}\right)$ to eliminate $l=L_{t}$ from (19). The result then follows from Assumption 1. The effects on this curve of changes in $y$ follow in the same way. From (20) and the properties of $l\left(N_{t}, Q_{t} / C_{t} \mid y\right)$ it follows that $\mathrm{D} N_{t}>0$ when $Q_{t} / C_{t}$ is above this curve. Using (21) and the properties of $l\left(N_{t}, Q_{t} / C_{t} \mid y\right)$ it is not difficult to verify that the curve $\mathrm{D}\left[Q_{t} / C_{t}\right]=0$ is downward sloping, that this curve shifts down with an increase in $y$, and that $\mathrm{D}\left[Q_{t} / C_{t}\right]>0$ when $Q_{t} / C_{t}$ is above this curve. This implies standard saddle-point dynamics with a downward-sloping stable manifold. As expected, the shadow price of new projects is a decreasing function of the stock $N_{t}$.

Combined with Lemma 1, the downward-sloping stable manifold implies that $C_{t}$ and $N_{t}$ must move in the same direction along an equilibrium trajectory. Consumption and the stock of new projects move together. An immediate corollary is that interest rates exceed the subjective discount rate $\rho$ as long as $N_{t}$ is below the steady state. Since new project prices are just the profits $1-\psi$ discounted at the rates $\left\{r_{s}+\delta\right\}_{s \geq t}$, this implies that $Q_{t}$ is below its steady state when $N_{t}$ is, even though $Q_{t} / C_{t}$ is high. The low $Q_{t}$ also means that the managerial wage $p_{t}=\gamma Q_{t}$ is low relative to the steady state. Since $\psi=w_{t}+p_{t}$ this implies the wages of workers are high. The Frisch labor supply curve $w_{t}=\xi C_{t} L_{t}^{1 / \varepsilon}$ and the fact that $C_{t}$ is below its steady state imply that $L_{t}$ is above its steady state when $N_{t}$ is low. The following proposition summarizes this discussion.

Proposition 1 Suppose old projects are in use and $N_{t}$ is below its steady state. Then $C_{t}, p_{t}$, and $Q_{t}$ are below their steady states, and $L_{t}, w_{t}$ and $r_{t}$ are above their steady states.

In order to compare ex post steady states with the ex ante steady state that arises before consumers learn $\tau$ or $\sigma$, it will be important to know how $Q_{t} / C_{t}$ is affected by the outside source $y$. The fact that $Q_{t} / C_{t}$ is proportional to a present value of $L_{t}^{1 / \varepsilon}$ discounted at a constant rate means that trajectories with low $L_{t}$ must also have low $Q_{t} / C_{t}$. This can be used to argue that $Q_{t} / C_{t}$ is a decreasing function of $y$. We already know that this is true in the steady state. To show $Q_{t} / C_{t}$ is also decreasing in $y$ for any given $N_{t}$, consider a high- $y$ and a low- $y$ economy, and suppose the equilibrium trajectories of these two economies cross. Since $l\left(N_{t}, Q_{t} / C_{t} \mid y\right)$ is decreasing in $y$, the high-y economy must have a lower $L_{t}$ at this point. The differential equation (20)-(21) therefore implies that $\mathrm{D} N_{t}$ and $\mathrm{D}\left[Q_{t} / C_{t}\right]$ are higher in the high- $y$ economy than in the low- $y$ economy. As a result, the conjectured equilibrium trajectories for the two economies start to diverge, in a way that raises $y+(1-\psi) N_{t}$ and $Q_{t} / C_{t}$ in the high- $y$ economy relative to the low- $y$ 
economy. But then (18) implies even lower values for $L_{t}$ in the high-y economy than in the low- $y$ economy. As argued, the present-value representation for $Q_{t} / C_{t}$ says that then the high- $y$ economy must then also have a lower $Q_{t} / C_{t}$ than the low- $y$ economy, which is not consistent with the conjectured equilibrium trajectories that would emanate from a point where these trajectories cross. This contradiction implies that the equilibrium trajectories of high-y and low-y economies cannot cross. Because the stable manifolds cut the $\mathrm{D}\left[Q_{t} / C_{t}\right]=0$ curves from below, it follows that equilibrium trajectories must be ranked as they are in their respective steady states. An immediate corollary of this and Lemma 1 is that $C_{t}$ is high when $y$ is high. This proves the following proposition.

Proposition 2 Consider economies in which old projects are in use. Then $Q_{t} / C_{t}=$ $\Lambda\left(N_{t} \mid y\right)$ is a decreasing function and $C_{t}=C\left(N_{t} \mid y\right)$ is an increasing function of the outside source of income $y$.

\subsection{The Ex Ante Economy}

The possible jump of the outside source of consumption $y_{t}$ and the possible arrival of a signal that it will never happen imply a need for state-contingent claims. Since there are only two transitions, it is enough to augment a "bank account" earning the risk-free rate $r_{t}$ with two contingent claims, one that pays one unit of wealth (measured in units of consumption) precisely when $y_{t}$ jumps, and one that pays one unit of wealth when it is learned that $y_{t}$ will not jump.

To describe the equilibrium conditions, let all time derivatives represent left-derivatives: derivatives that apply while $y_{t}=y_{\mathrm{L}}$ and no negative signal has been revealed. So $\mathrm{D} C_{t} / C_{t}$ is consumption growth conditional on this state. Recall that $\theta_{t}$ is the posterior belief at time $t$ that $y_{t}$ will increase eventually. Let $\theta_{t} \alpha f_{\mathrm{H}, t}$ and $\left(1-\theta_{t}\right) \beta f_{\mathrm{L}, t}$ be the flow insurance premia that consumers can pay in exchange for one unit of wealth contingent on, respectively, a jump in $y_{t}$ and a signal that $y_{t}$ will never jump. The equilibrium condition for the risk-free rate is no longer the ex-post Euler condition (12) but

$$
r_{t}=\rho+\frac{\mathrm{D} C_{t}}{C_{t}}+\theta_{t} \alpha\left(1-f_{\mathrm{H}, t}\right)+\left(1-\theta_{t}\right) \beta\left(1-f_{\mathrm{L}, t}\right) .
$$

To see this, consider a risky bank account that pays an interest rate $\theta_{t} \alpha+\left(1-\theta_{t}\right) \beta+R_{t}$ as long as $y_{t}=y_{\mathrm{L}}$ and no negative signal has been received, and then drops to zero upon the arrival of either of these two events. Conditional on no change, the usual intertemporal trade-off implies $\theta_{t} \alpha+\left(1-\theta_{t}\right) \beta+R_{t}=\theta_{t} \alpha+\left(1-\theta_{t}\right) \beta+\rho+\mathrm{D} C_{t} / C_{t}$. The effective subjective discount rate $\theta_{t} \alpha+\left(1-\theta_{t}\right) \beta+\rho$ accounts for the fact that the 
state described by $\tau>t$ and $\sigma>t$ will not last, and $\mathrm{D} C_{t} / C_{t}$ is consumption growth conditional on this state. But this bank account is quite risky: the account is wiped out when $y_{t}$ jumps from $y_{\mathrm{L}}$ to $y_{\mathrm{H}}$ or the negative signal is received. Its expected return is not $\theta_{t} \alpha+\left(1-\theta_{t}\right) \beta+R_{t}$ but $R_{t}$. To insure this bank account, its owner can make flow payments $\theta_{t} \alpha f_{\mathrm{H}, t}+\left(1-\theta_{t}\right) \beta f_{\mathrm{L}, t}$ per unit of wealth held in the account. The loss of the bank account and the insurance payout will cancel when $y_{t}$ jumps or the negative signal is received. The expected return on the insured risky bank account is therefore $\theta_{t} \alpha+\left(1-\theta_{t}\right) \beta+R_{t}-\left[\theta_{t} \alpha f_{\mathrm{H}, t}+\left(1-\theta_{t}\right) \beta f_{\mathrm{L}, t}\right]=R_{t}+\theta_{t} \alpha\left(1-f_{\mathrm{H}, t}\right)+\left(1-\theta_{t}\right) \beta\left(1-f_{\mathrm{L}, t}\right)$. The insured bank account is risk free, and so its expected return must be the risk-free rate $r_{t}$. Since $R_{t}=\rho+\mathrm{D} C_{t} / C_{t}$, this implies (22).

During a small interval of time $\Delta$, the insurance premium $\theta_{t} \alpha f_{\mathrm{H}, t} \Delta$ entitles the insured consumer to one unit of wealth that pays out with approximate probability $\theta_{t} \alpha \Delta$. The insurance premium $f_{\mathrm{H}, t}$ "per unit of jump probability" is simply the relative price of a unit consumption just after a jump from $y_{\mathrm{L}}$ to $y_{\mathrm{H}}$ in units of consumption right before such a jump. This relative price must equal the marginal rate of substitution between consumption just before and just after the jump from $y_{\mathrm{L}}$ to $y_{t}=y_{\mathrm{H}}$. With a parallel argument for $f_{\mathrm{L}, t}$, this yields

$$
f_{\mathrm{H}, t}=\frac{C_{t}}{C\left(N_{t} \mid y_{\mathrm{H}}\right)}, \quad f_{\mathrm{L}, t}=\frac{C_{t}}{C\left(N_{t} \mid y_{\mathrm{L}}\right)},
$$

where $C_{t}$ is consumption in the ex ante economy and $C\left(N_{t} \mid y_{\mathrm{H}}\right)$ and $C\left(N_{t} \mid y_{\mathrm{L}}\right)$ are the equilibrium consumption levels in the two ex post economies that arise if $\tau=t$ and $\sigma=t$, respectively, given that the stock of new projects is $N_{t}$ at time $t$.

An important feature of $(22)$ is that changes in the beliefs $\theta_{t}$ break the tight connection between interest rates and consumption growth while $\tau>t$ and $\sigma>t$. As will be shown more formally below, basic consumption-smoothing logic indicates that $C\left(N_{t} \mid y_{\mathrm{L}}\right)<C_{t}<C\left(N_{t} \mid y_{\mathrm{H}}\right)$ when $y_{\mathrm{H}}>y_{\mathrm{L}}$, and so $(23)$ implies $f_{\mathrm{H}, t}<1<f_{\mathrm{L}, t}$. If $\beta>\alpha$ then $\theta_{t}$ is increasing over time, which tends to raise the interest rate as the weight on $1-f_{\mathrm{H}, t}>0$ increases and that on $1-f_{\mathrm{L}, t}<0$ declines. As $t$ becomes large, the posterior probability $\theta_{t}$ converges to 1 if $\beta>\alpha$, and then the Euler condition (22) implies a risk-free rate that is above the rate $\rho+\mathrm{D} C_{t} / C_{t}$ that an outside observer would infer not knowing that consumers consider the possibility that consumption might jump. ${ }^{16}$

New projects are risky assets. Their prices jump from $Q_{t}$ to the ex post equilibrium

\footnotetext{
${ }^{16}$ Appendix A explains (22) and (23) by taking limits in a discrete-time economy. There are no jumps in a discrete-time economy, and one can simply interpret the continuous-time Euler equation (22) as an approximation that is appropriate when consumption can change quickly from one period to the next.
} 
price $Q\left(N_{t} \mid y_{\mathrm{H}}\right)$ if the jump happens, and to $Q\left(N_{t} \mid y_{\mathrm{L}}\right)$ if the negative signal arrives at time $t$. New projects can be insured by maintaining insurance coverage at $Q_{t}-Q\left(N_{t} \mid y_{\mathrm{H}}\right)$ for the upward jump in $y_{t}$ and at $Q_{t}-Q\left(N_{t} \mid y_{\mathrm{L}}\right)$ for the arrival of the negative signal. The cost of this insurance is the sum of the respective flow insurance premia $\theta_{t} \alpha f_{\mathrm{H}, t}\left(Q_{t}-Q\left(N_{t} \mid y_{\mathrm{H}}\right)\right)$ and $\left(1-\theta_{t}\right) \beta f_{\mathrm{L}, t}\left(Q_{t}-Q\left(N_{t} \mid y_{\mathrm{L}}\right)\right)$. A project insured against these shocks is only exposed to the idiosyncratic risk of becoming an old project. It must therefore earn the risk-free rate. But the flow profits that accrue to such an insured new project are no longer $v_{t}$ but $v_{t}-\theta_{t} \alpha f_{t}\left(Q_{t}-Q\left(N_{t} \mid y_{\mathrm{H}}\right)\right)-\left(1-\theta_{t}\right) \beta f_{t}\left(Q_{t}-Q\left(N_{t} \mid y_{\mathrm{L}}\right)\right)$. It follows that

$$
r_{t} Q_{t}=v_{t}+\theta_{t} \alpha f_{\mathrm{H}, t}\left(Q\left(N_{t} \mid y_{\mathrm{H}}\right)-Q_{t}\right)+\left(1-\theta_{t}\right) \beta f_{\mathrm{L}, t}\left(Q\left(N_{t} \mid y_{\mathrm{L}}\right)-Q_{t}\right)+\mathrm{D} Q_{t}-\delta Q_{t} .
$$

The capital gain component $\mathrm{D} Q_{t}$ is deterministic and $-\delta Q_{t}$ is idiosyncratic. Because the project is insured, there is no further capital gain when $y_{t}$ jumps or the negative signal is received. For future reference, observe that the risk premium on new projects is $\theta_{t} \alpha\left(1-f_{\mathrm{H}, t}\right)\left(Q\left(N_{t} \mid y_{\mathrm{H}}\right)-Q_{t}\right)+\left(1-\theta_{t}\right) \beta\left(1-f_{\mathrm{L}, t}\right)\left(Q\left(N_{t} \mid y_{\mathrm{L}}\right)-Q_{t}\right)$.

The equilibrium in the ex ante economy is now determined by (2)-(9), the Euler condition (22), the asset pricing equation (24), and a transversality condition. As in the ex post economy, one can use the Euler equation (22) to eliminate the risk-free rate from the asset pricing equation (24) to obtain

$$
\left[\theta_{t} \alpha+\left(1-\theta_{t}\right) \beta+\rho+\delta\right]\left[\frac{Q_{t}}{C_{t}}\right]=\frac{v_{t}}{C_{t}}+\theta_{t} \alpha \Lambda\left(N_{t} \mid y_{\mathrm{H}}\right)+\left(1-\theta_{t}\right) \beta \Lambda\left(N_{t} \mid y_{\mathrm{L}}\right)+\mathrm{D}\left[\frac{Q_{t}}{C_{t}}\right],
$$

where $\Lambda\left(N_{t} \mid y\right)=Q\left(N_{t} \mid y\right) / C\left(N_{t} \mid y\right)$ is the shadow price of new projects in the ex post economy with $y_{t}=y$. The state of the ex ante economy is now $\left(\theta_{t}, N_{t}, Q_{t} / C_{t}\right)$ and the conditions for an equilibrium are summarized by (2)-(9), the intertemporal condition (25), and a transversality condition.

\subsection{The Ex Ante Steady State}

The ex ante steady state is the long-run equilibrium state that arises in the limit as $t \rightarrow \infty$, conditional on $\tau>t$ and $\sigma>t$. If $\alpha \neq \beta$ then the posterior probability $\theta_{t}$ converges to 0 or 1 , depending whether $\alpha$ or $\beta$ is larger. In the long run, the case $\alpha>\beta$ is equivalent to the prior $\theta=0$, and $\beta>\alpha$ is equivalent to the prior $\theta=1$. The knifeedge case of $\alpha=\beta$ implies $\theta_{t}=\theta$. One can thus study the various ex ante steady states by considering the case $\alpha=\beta$ and varying the prior belief $\theta \in[0,1]$. The case of interest is then $\theta=1$, since it corresponds to $\beta>\alpha$ and hence $\theta_{t} \uparrow 1$. Throughout the following, consider only steady states with $L>N$, so that teams of workers and managers are assigned to old projects and so that the factor price of new projects is $1-\psi$. 
The conditions for an ex ante steady state can be summarized by taking $y_{*}=y_{\mathrm{L}}$ and $y=y_{\mathrm{H}}$ in

$$
\begin{aligned}
& C=y_{*}+(1-\psi) N+\psi L, \quad \delta N=\gamma(H-L), \\
& \psi=\xi C L^{1 / \varepsilon}+p, \quad p=\gamma \times \frac{1-\psi+\alpha\left[\theta \Lambda(N \mid y)+(1-\theta) \Lambda\left(N \mid y_{\mathrm{L}}\right)\right] C}{\alpha+\rho+\delta} .
\end{aligned}
$$

The first of part of (26) is simply the resource constraint for consumption when $y_{t}=y_{*}$, and the second part follows from imposing the steady-state requirement $\mathrm{D} N_{t}=0$. The first part of (27) says that the shadow price of labor plus the managerial wage add up to the marginal product of a manager-worker team, which equals $\psi$ because old projects are assumed to be in use. The second part follows from $p_{t}=\gamma Q_{t}$ and setting $\mathrm{D}\left[Q_{t} / C_{t}\right]=0$ in (25), making use of $\beta=\alpha$ and $\theta_{t}=\theta$.

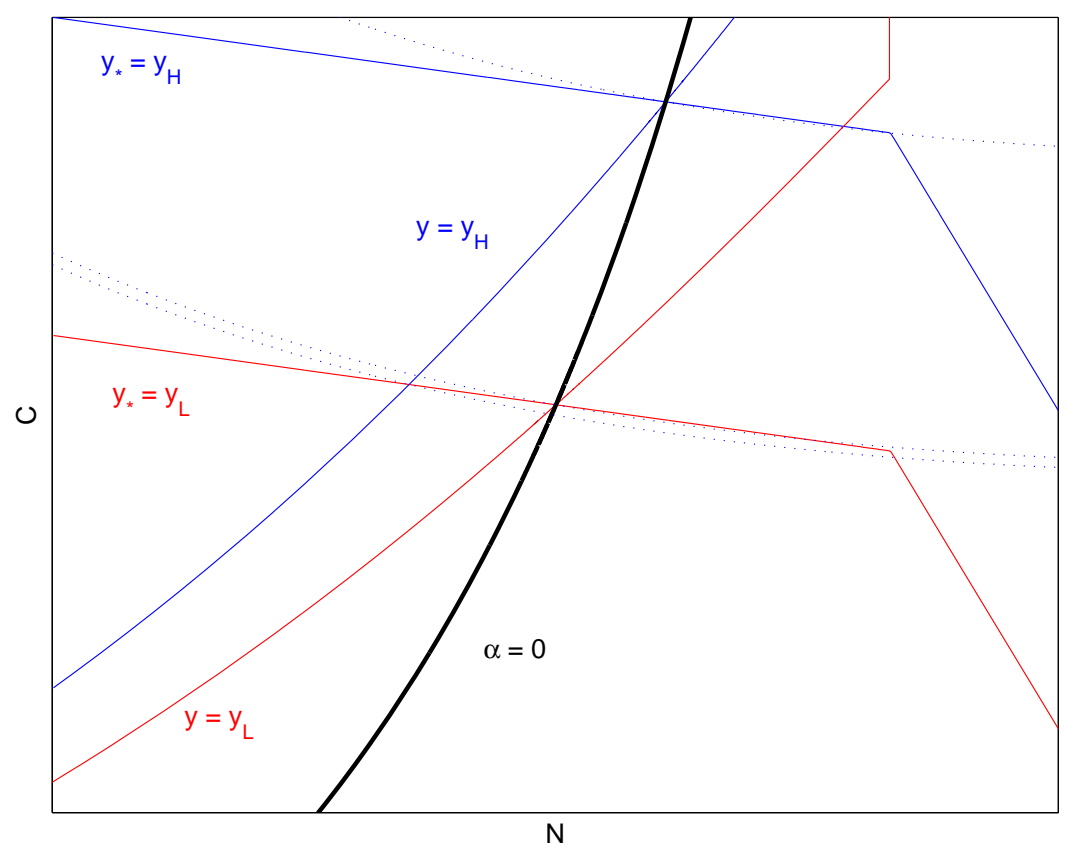

Figure 4 Ex Ante $(\theta=1)$ and Ex Post Steady States

The equilibrium conditions (26)-(27) also describe the $y_{t}=y$ ex post steady state if $y_{*}=y$ and $\theta=1$. To see this, observe that the equilibrium conditions (26) and the first part of (27) hold in any steady state with $y_{t}=y$. Since old projects are assumed to be in use, the factor price of new projects is $1-\psi$. This implies $p=(1-\psi) \gamma /(\rho+\delta)$ in any ex post steady state. Using this to eliminate $p$ from the second equation in (27) and solving for $\Lambda(N \mid y) C$ then gives $\Lambda(N \mid y) C=(1-\psi) /(\rho+\delta)$, which is indeed the price 
of new projects in any ex post steady state. To summarize, (26)-(27) describes the ex ante steady state when $y_{*}=y_{\mathrm{L}}$ and $y=y_{\mathrm{H}}$ and an ex post steady state when $y_{*}=y$ and $\theta=1$.

Now compare ex ante and ex post steady states by varying $y_{*}$ and $y$ in (26)-(27). Eliminate $L$ and $p$ from (26)-(27) and rewrite the result as

$$
\begin{aligned}
C & =y_{*}+\psi H-(1-\psi)\left(\frac{\psi}{1-\psi}-\frac{\gamma}{\delta}\right) \frac{\delta N}{\gamma}, \\
C & =\frac{(1-\psi)\left(\frac{\psi}{1-\psi}-\frac{\gamma}{\rho+\alpha+\delta}\right)}{\xi\left(H-\frac{\delta N}{\gamma}\right)^{1 / \varepsilon}+\frac{\alpha \gamma}{\rho+\alpha+\delta}\left[\theta \Lambda(N \mid y)+(1-\theta) \Lambda\left(N \mid y_{\mathrm{L}}\right)\right]} .
\end{aligned}
$$

These equilibrium conditions are shown in Figure 4 for $\theta=1, y_{*} \in\left\{y_{\mathrm{L}}, y_{\mathrm{H}}\right\}$ and $y \in$ $\left\{y_{\mathrm{L}}, y_{\mathrm{H}}\right\}$, along with the indifference curves of $\ln (C)-\xi(H-\delta N / \gamma)^{1+1 / \varepsilon} /(1+1 / \varepsilon)$ associated with the respective steady states. Because $\delta N=\gamma(H-L)$ in any steady state, consumers like more consumption and more new projects. ${ }^{17}$ The equilibrium condition (28) is a steady-state resource constraint that incorporates the technology for producing consumption and the steady-state condition $\mathrm{D} N_{t}=0$. As noted before, Assumption 1 implies that (28) is downward sloping. Condition (29) incorporates the marginal conditions for prices, as well as both steady state requirements $\mathrm{D} N_{t}=0$ and $\mathrm{D} Q_{t}=0$. Assumption 1 ensures that $C$ is positive (no steady state can have more projects than can be maintained by managers, and hence $H-\delta N / \gamma \geq 0$.) The shadow price $\Lambda(N \mid y)$ is decreasing in the stock of new projects $N$, and so (29) is increasing in $N$. By Proposition 2, $\Lambda(N \mid y)$ is decreasing in $y$, and hence the curve (29) shifts up with an increase in $y$. Ex post steady states can be determined by taking $y=y_{*}$ in (28)-(29) and $\theta=1$. This yields two steady states, one for each $y=y_{*} \in\left\{y_{\mathrm{L}}, y_{\mathrm{H}}\right\}$. More generally, setting $\alpha=0$ in (29) gives a curve that does not depend on $y$, represented by the solid curve in Figure 4. Varying $y_{*}$ in $(28)$ then traces out ex post steady states for various $y=y_{*}$. The intersection of (28) with $y_{*}=y_{\mathrm{L}}$ and (29) with $y=y_{\mathrm{H}}$ determines the ex ante steady state implied by $\beta>\alpha$. The segment of (28) in between this intersection and the $y_{t}=y_{\mathrm{L}}$ ex post steady states describes the ex ante steady states for $\beta=\alpha$ and $\theta \in[0,1]$.

A comparison of the ex ante steady state and the ex post steady states for $y_{\mathrm{L}}$ and

\footnotetext{
${ }^{17}$ The marginal product of labor is $\psi-(1-\psi) \gamma / \delta$ across steady states in which old projects are in use. The marginal rate of substitution is $\psi-(1-\psi) \gamma /(\rho+\delta)$ in ex post steady states. The indifference curves in Figure 4 are only slightly steeper than the steady-state resource constraints (28) because $\rho$ is taken to be a small positive number.
} 
$y_{\mathrm{H}}$ is given in Proposition 3. The main observation is that the number of new projects is lower in any ex ante steady state that it is in either of the two ex post steady states.

Proposition 3 Suppose $\beta>\alpha$. Consider steady state equilibria in which old projects are in use. Then

\begin{tabular}{lccccccc}
\hline & $N$ & $C$ & $L$ & $w$ & $p$ & $Q / C$ & $r$ \\
\hline ex post $y_{t}=y_{\mathrm{L}}$ & medium & low & medium & low & high & high & low \\
ex post $y_{t}=y_{\mathrm{H}}$ & high & high & low & low & high & low & low \\
ex ante $y_{t}=y_{\mathrm{L}}$ & low & medium & high & high & low & medium & high \\
\hline
\end{tabular}

For $N$ and $C$, the comparisons between the two ex post steady states are immediate from (15) and (16), or from the fact that the $\alpha=0$ curve in Figure 4 is upward sloping. The ex post comparison for $L$ follows from $\delta N=\gamma(H-L)$, and we already know that $w, p$ and $Q$ do not depend on $y_{t}=y$ in the ex post steady state. The shadow price $Q / C$ is therefore inversely related to consumption across ex post steady states.

It remains to rank the ex ante steady state. Suppose first that $\theta=1$. Both $N$ and $C$ are higher in the $y_{t}=y_{\mathrm{H}}$ ex post steady state than in the ex ante steady state. To see this, notice that an increase in $y_{*}$ shifts the downward sloping curve (28) up and leaves the upwards sloping (29) unaffected. An increase in $y_{*}$ from $y_{*}=y_{\mathrm{L}}$ in the ex ante steady state to $y_{*}=y_{\mathrm{H}}$ in the $y_{t}=y_{\mathrm{H}}$ ex post steady state therefore implies an increase in both $C$ and $N$. To compare the ex ante steady state with the $y_{t}=y_{\mathrm{L}}$ ex post steady state, keep $y_{*}=y_{\mathrm{L}}$ and reduce $y$ from $y_{\mathrm{H}}$ to $y_{\mathrm{L}}$. By Proposition $2, \Lambda(N \mid y)$ is decreasing in $y$. A reduction in $y$ therefore shifts the upward sloping curve (29) down. This increases $N$ and lowers $C$. Hence $N$ is higher and $C$ is lower in the $y_{t}=y_{\mathrm{L}}$ ex post steady state than in the ex ante steady state. The case $\theta \in(0,1]$ is implied because (29) is in between the versions of (29) that apply when $\theta \in\{0,1\}$.

This establishes the ranking of $N$ and $C$ across all steady states, and the ranking of $L$ is implied by $\delta N=\gamma(H-L)$. Worker wages are higher in the ex ante steady state than they are in the two ex post steady states because $w=\xi C L^{1 / \varepsilon}$ and $C$ and $L$ are higher in the ex ante steady state than they are in the $y_{t}=y_{\mathrm{L}}$ ex post steady state. The ranking of managerial wages is then immediate from $\psi=w+p$. Since $p=\gamma Q$, this also implies a ranking of new project prices. Now consider the ranking of the shadow price $Q / C$. The comparison between the ex ante steady state and the $y_{t}=y_{\mathrm{L}}$ ex post steady state follows from the ranking of $Q=p / \gamma$ and $C$ across these steady states. The comparison between the ex ante steady state and the $y_{t}=y_{\mathrm{H}}$ ex post steady state 
follows from dividing the second equation in (27) by $\gamma C$ and noting that $(1-\psi) / C$ and $\Lambda\left(N \mid y_{\mathrm{H}}\right)$ are decreasing in $C$ and $N$, respectively.

It remains to rank the interest rates. The key step in showing the ranking given in Proposition 3 is the following lemma, which is proved in the Appendix.

Lemma 2 The ex ante steady state $(N, Q / C)$ satisfies $Q / C \in\left[\Lambda\left(N \mid y_{\mathrm{H}}\right), \Lambda\left(N \mid y_{\mathrm{L}}\right)\right]$.

Since consumption is constant in any steady state, the interest rate is given by $r=\rho$ in both ex post steady states, and by $r=\rho+\alpha\left(1-f_{\mathrm{H}}\right)$ in the ex ante steady state associated with $\beta>\alpha$. Lemma 2 implies that, starting from the ex ante steady state, the arrival of $\tau \leq t$ causes $Q / C$ to jump down to $\Lambda\left(N \mid y_{\mathrm{H}}\right)$. Since $y_{t}$ jumps up from $y_{\mathrm{L}}$ to $y_{\mathrm{H}}$, Lemma 1 then implies that consumption jumps up from the ex ante steady state value $C$ to $C\left(N \mid y_{\mathrm{H}}\right)>C$. Hence $f_{\mathrm{H}}=C / C\left(N \mid y_{\mathrm{H}}\right)<1$ and thus $r>\rho$, completing the proof of Proposition 3.

Proposition 4 gives a more complete characterization of the jumps that will occur when the events $\tau \leq t$ or $\sigma \leq t$ arrive.

Proposition 4 The ex ante steady state $(N, Q / C)$ satisfies $Q / C \in\left[\Lambda\left(N \mid y_{\mathrm{H}}\right), \Lambda\left(N \mid y_{\mathrm{L}}\right)\right]$. Consumption satisfies $C \in\left[C\left(N \mid y_{\mathrm{L}}\right), C\left(N \mid y_{\mathrm{H}}\right)\right]$, and $L$ exceeds both $L\left(N \mid y_{\mathrm{L}}\right)$ and $L\left(N \mid y_{\mathrm{H}}\right)$.

The first part of this is Lemma 2, and the proof of Proposition 3 shows that $C<$ $C\left(N \mid y_{\mathrm{H}}\right)$. Since $C=y_{\mathrm{L}}+(1-\psi) N+\psi L$ in the ex ante steady state, the inequality $C>C\left(N \mid y_{\mathrm{L}}\right)$ is equivalent to $L>L\left(N \mid y_{\mathrm{L}}\right)$. But this follows from the fact that $\mathrm{D} N_{t}>0$ immediately following the negative signal. At the time that all uncertainty is resolved, worker employment will drop, whether the news is good or bad. ${ }^{18}$

\subsection{The Ex Ante Equilibrium}

In the ex ante regime, the state of the economy is $\left(\theta_{t}, N_{t}, Q_{t} / C_{t}\right)$. The posterior remains constant at $\theta_{t}=\theta$ when $\beta=\alpha$, effectively reducing the state to $\left(N_{t}, Q_{t} / C_{t}\right)$. When $\beta \neq \alpha$ the state simplifies to $\left(N_{t}, Q_{t} / C_{t}\right)$ only in the long run, as $\theta_{t}$ converges to 0 or 1 . But the posterior evolves by itself and this makes it possible to characterize the ex ante trajectories in some detail. From Proposition 2 we already know that the ex post trajectories are ranked and decreasing in $y_{t}$. Using a similar proof, given in the appendix, one can show that the ex ante trajectories for $\left(N_{t}, Q_{t} / C_{t}\right)$ are in between the ex post trajectories for $y_{t}=y_{\mathrm{L}}$ and $y_{t}=y_{\mathrm{H}}$.

\footnotetext{
18 "Good news" here means an immediate increase in the outside source of income. See below for the good news associated with a smooth increase in $\theta_{t}$.
} 
Proposition 5 Consider an economy with a prior belief $\theta \in[0,1]$ in which old projects are in use at all times. Then the equilibrium trajectory satisfies $Q_{t} / C_{t} \in$ $\left[\Lambda\left(N_{t} \mid y_{\mathrm{H}}\right), \Lambda\left(N_{t} \mid y_{\mathrm{L}}\right)\right]$.

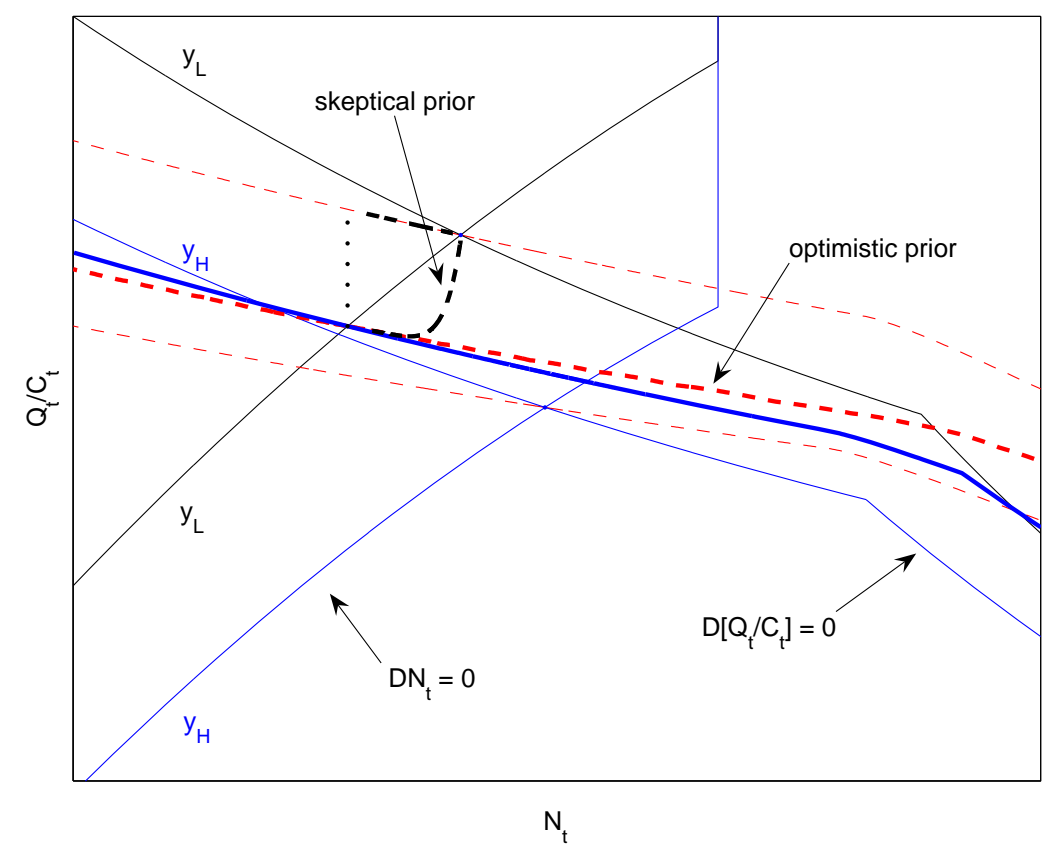

Figure 5 Ex Post and Ex Ante Equilibrium Trajectories

Consider the case $\beta>\alpha$ so that, as long as $\theta>0$ and no negative signal arrives, consumers eventually come to believe that there will be an increase in the outside source of income. Figure 5 shows the $\mathrm{D} N_{t}=0$ and $\mathrm{D}\left[Q_{t} / C_{t}\right]=0$ curves, as well as the stable manifolds for the two ex post economies and for the ex ante economy associated with the (overly) optimistic prior $\theta=1$. The ex post equilibria are as in Figure 4 . The condition $\mathrm{D} N_{t}=0$ for the ex ante economy is the same as it is for the $y_{t}=y_{\mathrm{L}}$ ex post economy. The curve $\mathrm{D}\left[Q_{t} / C_{t}\right]=0$ for the ex ante economy is obtained from (25) with $C_{t}=c\left(N_{t}, Q_{t} / C_{t} \mid y_{\mathrm{L}}\right)$ and equilibrium profits that are given by $v_{t}=1-\psi$ as long as $L_{t}>N_{t}$. It is downward sloping, just like the $\mathrm{D}\left[Q_{t} / C_{t}\right]=0$ curves in the ex post economy. The ex ante equilibrium trajectory for the optimistic prior $\theta=1$ is in between the two ex post trajectories, as required by Proposition $5 .{ }^{19}$ An immediate

\footnotetext{
${ }^{19}$ The ex ante equilibrium conditions for $\beta=\alpha$ and $\theta \in(0,1)$ are also independent of time, because $\theta_{t}=\theta$. The equilibrium trajectory lies in between the trajectories for the $\theta=1$ ex ante equilibrium and the $y_{t}=y_{\mathrm{L}}$ ex post equilibrium that arises when $\theta=0$.
} 
implication is that $Q_{t} / C_{t}$ jumps down when the anticipated increase in the outside source of income arrives. The economy then begins to accumulate the larger stock of new projects associated with the $y_{t}=y_{\mathrm{H}}$ ex post long-run steady state.

If the negative signal $\tau=\infty$ arrives, unforeseen because of the optimistic prior $\theta=1$, then the economy becomes an ex post economy with $y_{t}=y_{\mathrm{L}}$. Proposition 5 and Figure 5 show that the equilibrium trajectory for this economy is everywhere above that for the $\theta=1$ ex ante economy, and so there will be an upward jump in $Q_{t} / C_{t}$. From the ex ante steady state, the economy again begins to accumulate more new projects. But in contrast to the case of positive news, the shadow price $Q_{t} / C_{t}$ now overshoots.

\subsubsection{The Skeptical Prior}

Also shown in Figure 5 is the equilibrium trajectory for an economy in which consumers start out with a skeptical prior: $\theta$ is positive but very close to zero. There might be a future increase in income, but consumers initially think it very unlikely. The equilibrium trajectory is shown for an economy that starts out with the number of new projects associated with $y_{t}=y_{\mathrm{L}}$ ex post steady state. Because $\theta$ is small, the initial value of $Q_{0} / C_{0}$ is only slightly below the value of this shadow price in the $y_{t}=y_{\mathrm{L}}$ ex post steady state. But then the evidence starts to build and the posterior $\theta_{t}$ converges to a belief that the outside source of income will eventually rise for sure. As this happens, the equilibrium trajectory converges to the ex ante stable manifold associated with the optimistic prior $\theta=1$. In Figure 5, the posterior changes more quickly than the stock of new projects, and the equilibrium trajectory gets close to the stable manifold for the $\theta=1$ economy while $N_{t}$ is still significantly above the $\theta=1$ ex ante steady state. Because the stable manifold for the $\theta=1$ ex ante economy is downward sloping, this then implies that the shadow price $Q_{t} / C_{t}$ overshoots.

Figure 6 shows more features of the equilibrium trajectory for this economy. The posterior beliefs change relatively quickly from a skeptical initial prior to virtual certainty that an increase in the outside source of consumption will occur eventually. The stock of new projects declines and is almost half-way towards the lower steady state associated with the $\theta=1$ dogmatic prior by the time $\theta_{t}$ is indistinguishable from 1 . With the rise in $\theta_{t}$ comes a decline in $Q_{t} / C_{t}$, from what it would be in the $y_{t}=y_{\mathrm{L}}$ ex post equilibrium to the lower values associated with the $\theta=1$ ex ante equilibrium. Since labor is given by $L_{t}=l\left(N_{t}, Q_{t} / C_{t} \mid y_{\mathrm{L}}\right)$, Lemma 1 implies that these declines in $N_{t}$ and $Q_{t} / C_{t}$ unambiguously increase worker employment. The lower $N_{t}$ tends to lower consumption and the lower $Q_{t} / C_{t}$ means that managers are cheap. Both effects increase 
the supply of labor. Consumption is given by $C_{t}=c\left(N_{t}, Q_{t} / C_{t} \mid y_{\mathrm{L}}\right)$ and the rapid initial decline in $Q_{t} / C_{t}$ dominates the effect of the decline in $N_{t}$, raising consumption as well. From Proposition 3 we know that both $C_{t}$ and $L_{t}$ will indeed be higher in the $\theta=1$ ex ante steady state than in the $y_{t}=y_{\mathrm{L}}$ ex post steady state. But along the $\theta=1$ stable manifold, $C_{t}$ and $N_{t}$ co-move, and so consumption must overshoot along with $Q_{t} / C_{t}$. The fact that both $C_{t}$ and $L_{t}$ increase as the economy moves from the $y_{t}=y_{\mathrm{L}}$ ex post steady state to the $\theta=1$ ex ante steady state implies an increase in the wages $w_{t}=\xi C_{t} L_{t}^{1 / \varepsilon}$ of workers as well. As already argued in Proposition 3, the interest rate in this ex ante steady state will be higher than it was in the $y_{t}=y_{\mathrm{L}}$ ex post steady state. Consumers are optimistic about a future increase in consumption, and this implies a higher interest rate. But consumption is virtually constant near the $\theta=1$ ex ante steady state, and an econometrician would be confronted with a Peso problem in relating consumption growth and interest rates near the ex ante steady state.

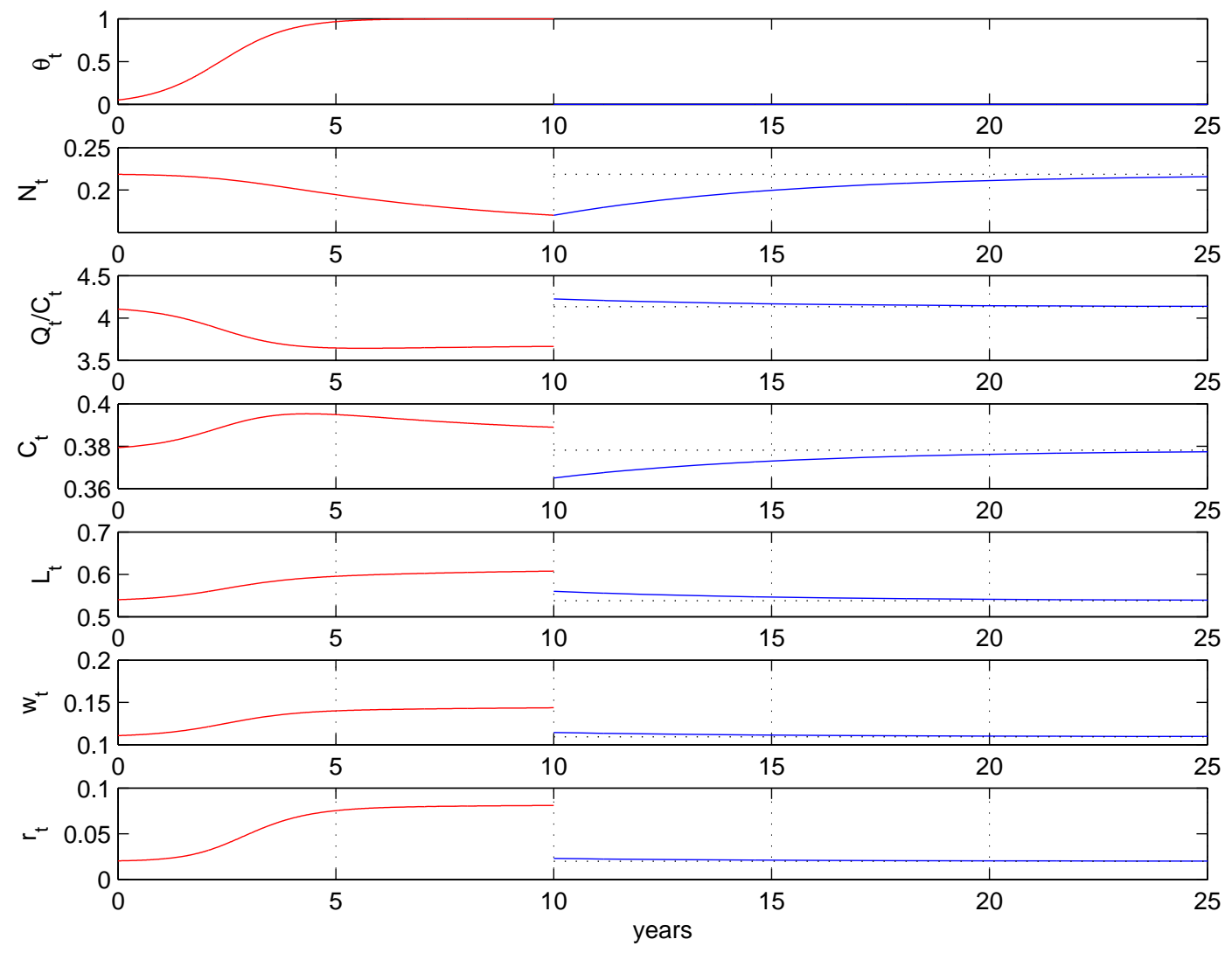

Figure 6 Recovering From a Bad Idea 
When the negative signal indicating $\tau=\infty$ does arrive at a time when $\theta_{t}$ is close to 1 , the shadow price $Q_{t} / C_{t}$ jumps upwards, onto the stable manifold for the $y_{t}=y_{\mathrm{L}}$ ex post economy. Because $L_{t} \in\left(N_{t}, H\right)$, the marginal cost of a team of managers and workers is $\psi=w_{t}+\gamma Q_{t}$, and hence $\psi=\left(\xi L_{t}^{1 / \varepsilon}+\gamma Q_{t} / C_{t}\right) C_{t}$ with $C_{t}=y_{\mathrm{L}}+(1-\psi) N_{t}+\psi L_{t}$. The increase in $Q_{t} / C_{t}$ therefore forces an immediate decline in $C_{t}$ and $L_{t}$, and an even stronger decline in the wages $w_{t}=\xi C_{t} L_{t}^{1 / \varepsilon}$ of workers. It follows that $p_{t}=\gamma Q_{t}$ must increase - managerial wages rise, though by less than the shadow price $Q_{t} / C_{t}$ because consumption falls. The unit cost of employment per project is stuck at $\psi$, but who receives this compensation shifts from workers to managers. The stock of new projects was too low in the ex ante steady state, and the economy returns to the $y_{t}=y_{\mathrm{L}}$ ex post steady state by having more managers create new projects. The ex post stable manifold is downward sloping, and so the initial jump in $Q_{t} / C_{t}$ is larger than the longrun response of this shadow price. Because $N_{t}$ increases and $Q_{t} / C_{t}$ declines towards the steady state, Lemma 1 implies that consumption increases towards the new steady state. The $y_{t}=y_{\mathrm{L}}$ ex post steady state has lower consumption than the ex ante steady state, and so consumption also overshoots. Consumption drops instantaneously when the $\tau=\infty$ news arrives and then begins to grow again. This positive consumption growth implies that, during the recovery, the real interest rate will remain above its ex post steady state value of $\rho$.

Since $Q_{t}$ is the present value of $1-\psi$, the price of new projects must recover from its initial drop as real interest rates decline towards their long-run steady state. It follows from $\psi=w_{t}+\gamma Q_{t}$ that wages must decline further after their initial drop. Together with $w_{t}=\xi C_{t} L_{t}^{1 / \varepsilon}$ and the recovery in consumption, this means that worker employment also continues to decline after the initial drop. In other words, the decline in wealth that results from the $\tau=\infty$ signal implies that consumption jumps down and then recovers, while worker employment drops down and continues to decline further to its new longrun steady state. Worker employment in ex post steady states is decreasing in the source of outside income. So an economy with a low source of outside income will have high worker employment. But employment in the ex ante economy employment is even higher, because the outside source of income is still low and consumers already want to consume more in anticipation of the future rise in income. Following the negative news $\tau=\infty$, worker employment will never return to these high levels. 


\subsubsection{Observed Employee Wages}

As argued, the recession generated by the news that $\tau=\infty$ increases managerial wages and lowers the wages of workers, as well as the amount of labor they supply. It is important to remember that these wages are the factor prices of tasks that employees can do, not necessarily the wages of actual employees who may very well be in jobs that require them to supply both tasks. The representative household can be interpreted as a household composed of individuals with heterogeneous managerial abilities. Let $\left[C_{t}(h), L_{t}(h)\right]$ be consumption and labor supply of an employee with an endowment of $h$ units of the managerial input. The complete markets assumption implies that the $\left[C_{t}(h), L_{t}(h)\right]$ are linear in the aggregates $\left[C_{t}, L_{t}\right]$. The individual levels of consumption and labor will be perfectly correlated with the aggregate. If individuals at the initial date differ only in terms of $h$ then the distribution of wealth is determined by $h$. Everyone is on the Frisch labor supply curve $w_{t}=\xi C_{t}(h)\left[L_{t}(h)\right]^{1 / \varepsilon}$, but high- $h$ individuals will be wealthier, consume more, and therefore supply less labor than low- $h$ individuals. Employee earnings are given by $w_{t} L_{t}(h)+p_{t} h$, and for employees with a high level of $h$ the $w_{t} L_{t}(h)$ component will be a small part of their total compensation. Their earnings will go up when the negative $\tau=\infty$ news hits. But for low- $h$ employees, this negative news has a large negative impact on earnings. Clearly, insurance is essential for the implementation of this allocation.

\subsubsection{Positive News}

The economy with a skeptical prior can be used examine what happens when consumers receive positive news about the future outside source of income. Taking $\beta$ to be very large, so that $\theta_{t} \uparrow 1$ almost instantaneously, approximates what happens when consumers receive a signal that $\tau<\infty$. The equilibrium trajectory will then reach the stable manifold of the ex ante economy almost instantaneously. By Lemma 1, the almost immediate drop in $Q_{t} / C_{t}$ implies an increase in both consumption and worker employment. It follows that the wages of workers jump up, and hence managerial wages and the prices of new projects have to decline. The positive news about the future generates a boom in consumption, worker employment, and worker wages.

\subsubsection{Unforeseen Changes in Government Purchases}

Suppose the economy is in the ex ante steady state. Then households suddenly learn that $\tau=\infty$. Worker wages and employment are set to go down. But suppose that in response, 
and unforeseen, the negative news is immediately followed by a permanent increase in government purchases. This lowers $y_{\mathrm{L}}$, which raises the $\mathrm{D} N_{t}=0$ and $\mathrm{D}\left[Q_{t} / C_{t}\right]=0$ curves in Figures 3 and 5, in a way that lowers the new steady state number of projects (just as $y_{\mathrm{L}}<y_{\mathrm{H}}$ implies fewer new projects in the $y_{t}=y_{\mathrm{L}}$ ex post steady state). The stable manifold must also shift up, by Proposition 2. A large enough increase in government purchases will reduce the new $y_{t}=y_{\mathrm{L}}$ ex post steady state measure of new projects to the level the economy started out with, in the ex ante steady state. Since $\delta N_{t}=\gamma\left(H-L_{t}\right)$ in both the ex ante steady state and the new ex post steady state, worker employment does not drop at all. With no change in $N_{t}$ or $L_{t}$, the decline in $y_{t}$ must be matched one-for-one by a decline in consumption, and $Q_{t} / C_{t}$ rises by just enough to ensure that the equilibrium conditions for employment (18)-(19) are satisfied. Because the economy is now in a steady state, the interest rate will be $\rho$, down from the higher interest rate in the ex ante steady state, when consumers were anticipating higher future consumption. Thus a large enough increase in government purchases can keep worker employment as high as it was in the ex ante steady state.

Conversely, a large enough reduction in government purchase can completely negate the $\tau=\infty$ news and instead put the economy on the equilibrium trajectory for the $y_{t}=y_{\mathrm{H}}$ ex post economy. The resulting increase in household wealth implies higher consumption and lower worker employment. It goes without saying that the welfare implications of these unforeseen changes in government purchases depend on how useful these purchases actually are. ${ }^{20}$

\subsection{Housing and Land}

Suppose the flow of consumption $C_{t}$ does not include expenditures on shelter. Instead, there is an aggregate flow $A_{t}$ of housing services that is generated by the stock of improved land and structures. This flow of housing services adds $\omega A_{t}^{1-1 / \eta} /(1-1 / \eta)$ to utility and the price of one unit of housing services in units of consumption is denoted by $s_{t}$. Everything about the economy described before continues to hold and the price of housing services is determined by $s_{t}=\omega C_{t} A_{t}^{-1 / \eta}$. A drop in consumption triggered by the signal that $\tau=\infty$ then causes a decline in the price of housing services, in the same proportion as the decline in consumption. If the flow of housing services is constant, then $s_{t}$ is proportional to $C_{t}$ at all times, and hence the capitalized value of $s_{t} A_{t}$ is proportional to the present value of consumption. The logarithmic preferences then imply

\footnotetext{
${ }^{20}$ The fact that distorting taxes may be needed to finance government purchases is being ignored here, as are the possible insurance benefits when shocks are unforeseen and markets are incomplete.
} 
that the present value of $s_{t} A_{t}$ is proportional to $C_{t} / \rho$. That is, the value of improved land and structures moves one-for-one with consumption. More drastic declines in house prices, such as those surrounding the US recession of 2008-2009, can be generated by an optimistic revision of beliefs about the future supply of land. But such a revision will have no effect on consumption and employment.

\section{VARiations ON This Theme}

The following sketches three important extensions of the baseline model that are still analytically tractable.

\subsection{Private Non-Residential Fixed Investment}

The negative signal $\sigma$ causes $L_{t}$ to drop and investment $\gamma Q_{t}\left(H-L_{t}\right)$ in new projects to jump up. The simplification that all investment is in intangible projects means that the model has no prediction for a notable empirical regularity across US business cycles: the employment-population ratio and the output share of private non-residential fixed investment are strongly positively correlated at business cycle frequencies. To account for this correlation, let $X_{t}$ be a stock of equipment and replace (2) and (4) by

$$
\begin{aligned}
C_{t}+\phi I_{t} & \leq y_{t}+(1-\psi) \min \left\{N_{t}, \min \left\{S_{t}, L_{t}\right\}\right\}+\psi \min \left\{S_{t}, L_{t}\right\} \\
\mathrm{D} X_{t} & \leq-\kappa X_{t}+I_{t}-S_{t},
\end{aligned}
$$

where $X_{t}, I_{t}$ and $S_{t}$ are required to be non-negative. As before, managers and workers need to operate in a team. But now such teams also need to use equipment services $S_{t}$. Equipment depreciates at the rate $\kappa$ independently of use. In contrast to new and old projects, equipment also depreciates with the use of equipment services $S_{t}$. Output can be used to produce not only consumption but also equipment, and the cost of one unit of equipment is $\phi$ units of consumption. This technology has an additional state variable that makes it hard to work out its implications analytically. But if $\kappa \uparrow \infty$ then $X_{t}$ drops out and the allocation will satisfy $I_{t}=S_{t}=L_{t}$. As a result, investment in new equipment moves one-for-one with worker employment. Assumption 1 needs to be replaced by $(\psi-\phi) /(1-\psi)>\gamma / \delta$ and then the results derived for the economy without equipment apply. 


\subsection{Irreversibilities}

The assumption that old projects stay around forever is a convenient simplification. It reduces the state variable $\left(N_{t}, K_{t}\right)$ of new and old projects to $N_{t}$ because $K_{t}$ will eventually be so large that it does not restrict output. An alternative assumption is the use-it-or-lose-it assumption: old projects that are not being used to produce consumption disappear. ${ }^{21}$ The ex post version of such an economy has the same steady state as an economy in which old projects stay around forever. More strongly, the equilibrium for an ex post economy without irreversibilities in which $K_{0}$ is high enough and $\delta N_{t}>$ $\mathrm{D} L_{t}-\mathrm{D} N_{t}$ along the equilibrium path is also the equilibrium for an ex post economy with irreversibilities. Such an economy has enough old projects to begin with and is creating more old projects than it can use. An example is the ex post equilibrium trajectory in Figure 6, where initial worker employment was high, worker employment declines, and the number of new projects is growing towards the new steady state.

An easy way to overturn this equivalence is to allow for the possibility that, by mistake, too many old projects are destroyed when the $\tau=\infty$ news is revealed. If $\delta N_{t}$ is high enough, such mistakes will be reversed relatively quickly, even if it takes a rather long time for $N_{t}$ itself to return to its steady state - as in Figure 6. To the extent that mistakes are more likely in periods of volatile inflation, this could be part of why US recessions during the 1970s and 1980s were followed by quicker employment recoveries than more recent recessions.

\subsection{When It Takes Projects to Create Projects}

Consider replacing the technology for creating new projects by (5) for $\mathrm{D} N_{t}$ by the more plausible

$$
\mathrm{D} N_{t}=G\left(N_{t}, H-L_{t}\right)+E .
$$

Here $E>0$ is a supply of new projects created from scratch by entrepreneurs, taken to be inelastic for simplicity. The function $G$ is a production function that exhibits constant returns to scale, and $G(0,1)=G(1,0)=0$. This production function is a replication technology that described how managers can take existing new projects to create more new projects. The assumption $G(0,1)=0$ means that managers cannot create new projects on their own, in contrast to the $G(0,1)=\gamma$ assumed so far. The

\footnotetext{
${ }^{21}$ An equivalent interpretation is that the technology for producing consumption is linear in worker labor up to a capacity constraint, provided a managerial fixed cost is incurred continuously. If the fixed cost is not paid, the project disappears. This is closely related to the model of firm heterogeneity used in Luttmer [2007].
} 
assumption $G(1,0)=0$ means that projects do not self-replicate. One can allow old projects to be replicated as well, but this is not worth the cost when old projects are abundant. Observe that there is joint production in this economy: new projects can be used to produce consumption goods, and to create new projects. But the managerial input is required for both.

Everything in this economy remains as before, except the asset pricing equation for new projects and the managerial wage $p_{t}$ for managers. In the ex ante economy, the asset pricing equation (24) has to be replaced by

$$
\begin{aligned}
r_{t} Q_{t}= & v_{t}+Q_{t} G\left(1, m_{t}\right)-p_{t} m_{t}+\mathrm{D} Q_{t}-\delta Q_{t} \\
& +\theta_{t} \alpha f_{\mathrm{H}, t}\left(Q\left(N_{t} \mid y_{\mathrm{H}}\right)-Q_{t}\right)+\left(1-\theta_{t}\right) \beta f_{\mathrm{L}, t}\left(Q\left(N_{t} \mid y_{\mathrm{L}}\right)-Q_{t}\right),
\end{aligned}
$$

where

$$
p_{t}=Q_{t} \mathrm{D}_{2} G\left(1, m_{t}\right)
$$

and $m_{t}$ is such that the market for managerial inputs clears, $H=L_{t}+m_{t} N_{t}$. The replacement for the asset pricing equation (13) for the ex post economy is obtained by setting $\alpha$ and $\beta$ to zero. Because existing new projects are an essential input for managers to be able to create new projects, this adds to the value of existing projects. At the same time, reallocating managers from producing consumption goods to creating new projects is now subject to decreasing returns. For a given change in $Q_{t}$, this tempers the dispersion in managerial and worker wages that can arise, and it will dampen fluctuations in $\mathrm{D} N_{t}$.

Economies of this type are studied in Luttmer [2011a, 2011b, 2012b]. As emphasized in Luttmer [2012b], the need to build on existing projects to create new projects can be an important limitation on how fast an economy can recover from a state in which $N_{t}$ is too low.

\section{Concluding Remarks}

Bayesian updating can lead consumers to become very optimistic about their wealth if the signal structure includes negative informative signals that are only revealed stochastically over time. No news is good news, and the longer there is no news, the more optimistic consumers become. In the economy described in this paper, this generates a consumption boom that goes along with higher employment for the types of labor used intensively in producing consumption goods. And it lowers the quality of the capital 
stock to a level below what it would be if consumers were more informed about their future income prospects.

The implications for wages of a negative wealth shock are more subtle than they are in models in which there is only one type of labor. Changes in the relative price of consumption and new projects have implications for the factor prices of the different types of labor that are used to produce consumption and new projects. Employees may be able to supply various types of labor. Employees are heterogeneous and the skill distribution is not one-dimensional. How the compensation of individual employees reacts to a negative wealth shock depends on the extent to which they can be used to create new projects. A caveat throughout is the strong maintained assumption that adequate insurance mechanisms are available to share risk within large households or across households. Imperfect insurance will affect the response of labor to low wages.

The belief shock that drives the results in this paper affects everyone simultaneously. An idea takes hold that incomes will rise, not just for particular groups of consumers, but for everyone. Moreover, everyone learns the negative news at the same time. It is likely that this strong coordination of beliefs involves learning from prices. More direct learning from others can also play a role, and this can give rise to cascades. Viewed from this perspective, it could be that an important aspect of the US financial crisis of the fall of 2008 was that it triggered a highly coordinated realization that previously held beliefs about aggregate wealth were too optimistic.

\section{A Continuous-Time Approximations}

Consider the grid $\mathcal{T}_{\Delta}=\{0, \Delta, 2 \Delta, \ldots\}$, where $\Delta>0$.

\subsection{The Posterior}

The following is the discrete-time version of (3). The prior probability of $\{\tau<\infty, \sigma=$ $\infty\}$ is $\theta \in(0,1)$, and the prior probability of $\{\tau=\infty, \sigma<\infty\}$ is $1-\theta$. Given $k-1<\tau<\infty$ the probability that $\tau=k$ is $a \in(0,1)$. Given $k-1<\sigma<\infty$ the probability that $\sigma=k$ is $b \in(0,1)$. Write $\theta_{0}=\theta$ and $\theta_{k-1}$ for the posterior probability of $\tau<\infty$ given the event $\tau>k-1$ and $\sigma>k-1$. In the event that $\tau>k$ and $\sigma>k$, this posterior is updated to

$$
\theta_{k}=\frac{\theta_{k-1}(1-a)}{\theta_{k-1}(1-a)+\left(1-\theta_{k-1}\right)(1-b)} .
$$


Note that this implies

$$
\theta_{k}-\theta_{k-1}=\frac{\theta_{k-1}\left(1-\theta_{k-1}\right)(b-a)}{\theta_{k-1}(1-a)+\left(1-\theta_{k-1}\right)(1-b)},
$$

and so $\theta_{k}$ will increase if $b>a$. To relate this to the continuous-time posterior (3), take $a=\alpha \Delta$ and $b=\beta \Delta$ for $\Delta>0$ sufficiently small. Then

$$
\theta_{k}-\theta_{k-1}=\frac{\theta_{k-1}\left(1-\theta_{k-1}\right)(\beta-\alpha) \Delta}{\theta_{k-1}(1-\alpha \Delta)+\left(1-\theta_{k-1}\right)(1-\beta \Delta)}
$$

Taking a limit as $\Delta \downarrow 0$ gives the logistic differential equation $\mathrm{D} \theta_{t}=(\beta-\alpha) \theta_{t}\left(1-\theta_{t}\right)$. Its solution is $(3)$.

\subsection{Interest Rates}

Again take $a=\alpha \Delta$ and $b=\beta \Delta$. Consumption during the time interval $[t, t+\Delta)$, where $t \in \mathcal{T}_{\Delta}$, is denoted by $C_{t} \Delta$ as long as $\tau>t$ and $\sigma>t$, and by $C_{\mathrm{H}, t} \Delta$ if $\tau \leq t$ and by $C_{\mathrm{L}, t} \Delta$ if $\sigma \leq t$. Let $q_{t}$ be the price at time $t \in \mathcal{T}_{\Delta}$ of a discount bond that pays one unit of wealth at time $t+\Delta$. Let $\theta_{t} \alpha \Delta \times f_{\mathrm{H}, t}$ be the price at time $t \in \mathcal{T}_{\Delta}$, as long as $\tau>t$ and $\sigma>t$, of one unit of consumption at $t+\Delta$ in case $\tau=t+\Delta$. Similarly, let $\left(1-\theta_{t}\right) \beta \Delta \times f_{\mathrm{L}, t}$ be the price at time $t \in \mathcal{T}_{\Delta}$, as long as $\tau>t$ and $\sigma>t$, of one unit of consumption at $t+\Delta$ in case $\sigma=t+\Delta$.

Logarithmic utility implies

$$
f_{\mathrm{H}, t}=\frac{e^{-\rho \Delta} C_{t}}{C_{\mathrm{H}, t+\Delta}}, \quad f_{\mathrm{L}, t}=\frac{e^{-\rho \Delta} C_{t}}{C_{\mathrm{L}, t+\Delta}} .
$$

At $t=k \Delta$, the price of a discount bond is

$$
\frac{q_{t}}{C_{t}}=e^{-\rho \Delta}\left[\frac{\theta_{k}(1-\alpha \Delta)+\left(1-\theta_{k}\right)(1-\beta \Delta)}{C_{t+\Delta}}+\frac{\theta_{k} \alpha \Delta}{C_{\mathrm{H}, t}}+\frac{\left(1-\theta_{k}\right) \beta \Delta}{C_{\mathrm{L}, t}}\right] .
$$

The interest rate from $t=k \Delta$ to $t+\Delta$ is $r_{t}=\left(1-q_{t}\right) / \Delta$, and thus

$$
\begin{aligned}
r_{t}= & \frac{1-e^{-\rho \Delta}}{\Delta} \\
& +e^{-\rho \Delta}\left(\frac{C_{t+\Delta}-C_{t}}{C_{t+\Delta} \Delta}+\theta_{k} \alpha\left[\frac{C_{t}}{C_{t+\Delta}}-\frac{C_{t}}{C_{\mathrm{H}, t}}\right]+\left(1-\theta_{k}\right) \beta\left[\frac{C_{t}}{C_{t+\Delta}}-\frac{C_{t}}{C_{\mathrm{L}, t}}\right]\right) .
\end{aligned}
$$

As $\Delta \downarrow 0$, this converges to

$$
r_{t}=\rho+\frac{\mathrm{D} C_{t}}{C_{t}}+\theta_{t} \alpha\left(1-f_{\mathrm{H}, t}\right)+\theta_{t} \beta\left(1-f_{\mathrm{L}, t}\right)
$$

where $f_{\mathrm{H}, t}=C_{t} / C_{\mathrm{H}, t}, f_{\mathrm{L}, t}=C_{t} / C_{\mathrm{L}, t}$, and where $\mathrm{D} C_{t} / C_{t}$ is consumption growth conditional on $\tau>t$ and $\sigma>t$. This corresponds to (22) and (23) in the text. 


\section{B Proof of Lemma 2}

Write $\omega=\rho+\delta-(1-\psi) \gamma / \psi$ and note that Assumption 1 implies that $\omega>\rho$.

Refer to Figure 5. The ex ante steady state must be on the $\mathrm{D} N_{t}=0$ curve for the $y_{t}=y_{\mathrm{L}}$ ex post economy. That is, the ex ante steady state $(N, \Lambda)$ must satisfy $\delta N=\gamma\left(H-l\left(N, \Lambda \mid y_{\mathrm{L}}\right)\right)$. Define the state $\left(N_{t}, \Lambda_{t}\right)$ by

$$
\delta N_{t}=\gamma\left(H-l\left(N_{t}, \Lambda_{t} \mid y_{\mathrm{L}}\right)\right), \quad\left(N_{t}, \Lambda_{t}\right)=\left(N_{t}, \Lambda\left(N_{t} \mid y_{\mathrm{H}}\right)\right)
$$

Thus $\left(N_{t}, \Lambda_{t}\right)$ is at the intersection of the $\mathrm{D} N_{t}=0$ curve for the $y_{t}=y_{\mathrm{L}}$ ex post economy with the stable manifold for the $y_{t}=y_{\mathrm{H}}$ ex post economy. At this intersection, $N_{t}$ is below the $y_{t}=y_{\mathrm{H}}$ ex post steady state, and thus $\mathrm{D} N_{t}>0$ and $\mathrm{D} \Lambda_{t}<0$ in the $y_{t}=y_{\mathrm{H}}$ ex post equilibrium. This means that employment $L_{t}$ in the $y_{t}=y_{\mathrm{H}}$ ex post equilibrium satisfies

$$
\mathrm{D} N_{t}=-\delta N_{t}+\gamma\left(H-L_{t}\right)>0>\omega \Lambda_{t}-\frac{(1-\psi) \xi L_{t}^{1 / \varepsilon}}{\psi}=\mathrm{D} \Lambda_{t}
$$

The first inequality implies $L_{t}<l\left(N_{t}, \Lambda_{t} \mid y_{\mathrm{L}}\right)$. Combining this with the second inequality and $\Lambda_{t}=\Lambda\left(N_{t} \mid y_{\mathrm{H}}\right)<\Lambda\left(N_{t} \mid y_{\mathrm{L}}\right)$ gives

$$
(\alpha+\omega) \Lambda_{t}<\frac{(1-\psi) \xi\left[l\left(N_{t}, \Lambda_{t} \mid y_{\mathrm{L}}\right)\right]^{1 / \varepsilon}}{\psi}+\alpha\left[\theta \Lambda\left(N_{t} \mid y_{\mathrm{H}}\right)+(1-\theta)\left(N_{t} \mid y_{\mathrm{L}}\right)\right]
$$

But this must be an equality in the ex ante steady state. Lowering $\left(N_{t}, \Lambda_{t}\right)$ along the $\mathrm{D} N_{t}=0$ curve for the $y_{t}=y_{\mathrm{L}}$ ex post economy would lower $\Lambda_{t}$, increase $l\left(N_{t}, \Lambda_{t} \mid y_{\mathrm{L}}\right)$, and it would increase $\Lambda\left(N_{t} \mid y_{\mathrm{H}}\right)$ and $\Lambda\left(N_{t} \mid y_{\mathrm{L}}\right)$, thus widening the gap between the leftand right-hand sides of this inequality. It follows that the ex ante steady state must be to the right and above the intersection $\left(N_{t}, \Lambda_{t}\right)$.

Alternatively, suppose $\left(N_{t}, \Lambda_{t}\right)$ is the $y_{t}=y_{\mathrm{L}}$ ex post steady state. Then $\mathrm{D} \Lambda_{t}=0$ and $\Lambda_{t}=\Lambda\left(N_{t} \mid y_{\mathrm{L}}\right)>\Lambda\left(N_{t} \mid y_{\mathrm{H}}\right)$ imply

$$
(\alpha+\omega) \Lambda_{t}>\frac{(1-\psi) \xi\left[l\left(N_{t}, \Lambda_{t} \mid y_{\mathrm{L}}\right)\right]^{1 / \varepsilon}}{\psi}+\alpha\left[\theta \Lambda\left(N_{t} \mid y_{\mathrm{H}}\right)+(1-\theta) \Lambda\left(N_{t} \mid y_{\mathrm{L}}\right)\right]
$$

From this point, increasing $\left(N_{t}, \Lambda_{t}\right)$ along the $\mathrm{D} N_{t}=0$ curve for the $y_{t}=y_{\mathrm{L}}$ ex post economy would raise $\Lambda_{t}$, lower $l\left(N_{t}, \Lambda_{t} \mid y_{\mathrm{L}}\right)$, and it would lower $\Lambda\left(N_{t} \mid y_{\mathrm{H}}\right)$ and $\Lambda\left(N_{t} \mid y_{\mathrm{L}}\right)$. Hence the ex ante steady state must be below and to the left of the steady state of the $y_{t}=y_{\mathrm{L}}$ ex post economy.

Together with the fact that $\Lambda(n \mid y)$ is a downward-sloping function of $n$ for any $y$, these two observations prove Lemma 2. 


\section{Proof of Proposition 5}

Recall that $\omega=\rho+\delta-(1-\psi) \gamma / \psi>0$.

\subsection{Ex Post Equilibria}

The ex post equilibrium for $y_{t}=y$ satisfies the differential equation

$$
\begin{aligned}
& \mathrm{D} N_{t}=-\delta N_{t}+\gamma\left[H-l\left(N_{t}, \Lambda_{t} \mid y\right)\right] \\
& \mathrm{D} \Lambda_{t}=\omega \Lambda_{t}-\left(\frac{1-\psi}{\psi}\right) \xi\left[l\left(N_{t}, \Lambda_{t} \mid y\right)\right]^{1 / \varepsilon} .
\end{aligned}
$$

Define $N_{t}^{*}=N_{t} e^{\delta t}$ and $\Lambda_{t}^{*}=\Lambda_{t} e^{-\omega t}$. Then this differential equation is of the form $\mathrm{D}\left[N_{t}^{*}, \Lambda_{t}^{*}\right]=\left[F_{t}\left(N_{t}^{*}, \Lambda_{t}^{*} \mid y\right), G_{t}\left(N_{t}^{*}, \Lambda_{t}^{*} \mid y\right)\right]$. The functions $F_{t}(n, \lambda \mid y)$ and $G_{t}(n, \lambda \mid y)$ are increasing in $n, \lambda$ and $y$. This means that the solutions for $\left[N_{t}^{*}, \Lambda_{t}^{*}\right]$ starting from a common $\left[N_{0}^{*}, \Lambda_{0}^{*}\right]=\left[N_{0}, \Lambda_{0}\right]$ are increasing in $y$. The same must then be true for $\left[N_{t}, \Lambda_{t}\right]=\left[N_{t}^{*} e^{-\delta t}, \Lambda_{t}^{*} e^{\omega t}\right]$. Since these trajectories must converge to their respective steady states, it would follow that the steady state values $[N, \Lambda]$ are increasing in $y$. Proposition 3 implies that this is true for $N$, but not for $\Lambda$. This contradiction means that the equilibrium trajectories for different $y$ cannot cross.

This fact, the ranking of the $\mathrm{D} \Lambda_{t}=0$ curves, and the fact that the stable manifolds cross the $\mathrm{D} \Lambda_{t}=0$ curves from below implies that the stable manifolds are ranked as they are in the steady state.

\subsection{Ex Ante and Ex Post Equilibria}

Let $\theta_{t} \in(0,1)$ be the posterior $(3)$. Consider the differential equation

$$
\begin{aligned}
\mathrm{D} N_{t}= & -\delta N_{t}+\gamma\left[H-l\left(N_{t}, \Lambda_{t} \mid y\right)\right] \\
\mathrm{D} \Lambda_{t}= & \left(\theta_{t} \alpha+\left(1-\theta_{t}\right) \beta+\omega\right) \Lambda_{t} \\
& -\left[\left(\frac{1-\psi}{\psi}\right) \xi\left[l\left(N_{t}, \Lambda_{t} \mid y\right)\right]^{1 / \varepsilon}+\theta_{t} \alpha \Lambda\left(N_{t} \mid y_{\alpha}\right)+\left(1-\theta_{t}\right) \beta \Lambda\left(N_{t} \mid y_{\beta}\right)\right] .
\end{aligned}
$$

The ex ante equilibrium satisfies this differential equation for $y=y_{\beta}=y_{\mathrm{L}}$ and $y_{\alpha}=y_{\mathrm{H}}$, as long as old projects are in use. Define

$$
N_{t}^{*}=N_{t} e^{\delta t}, \quad \Lambda_{t}^{*}=\Lambda_{t} \exp \left(-\int_{0}^{t}\left(\theta_{s} \alpha+\left(1-\theta_{s}\right) \beta+\omega\right) \mathrm{d} s\right) .
$$

The differential equation for $\left[N_{t}^{*}, \Lambda_{t}^{*}\right]$ is of the form

$$
\mathrm{D}\left[N_{t}^{*}, \Lambda_{t}^{*}\right]=\left[F_{t}\left(N_{t}^{*}, \Lambda_{t}^{*} \mid y\right), G_{t}\left(N_{t}^{*}, \Lambda_{t}^{*} \mid y, y_{\alpha}, y_{\beta}\right)\right]
$$


The functions $F_{t}(n, \lambda \mid y)$ and $G_{t}\left(n, \lambda \mid y, y_{\alpha}, y_{\beta}\right)$ are increasing in all their arguments.

To compare the ex ante equilibrium with the $y_{t}=y_{\mathrm{L}}$ ex post equilibrium, start with the solution for $\left(y, y_{\alpha}, y_{\beta}\right)=\left(y_{\mathrm{L}}, y_{\mathrm{H}}, y_{\mathrm{L}}\right)$, and then lower $y_{\alpha}$ to $y_{\mathrm{L}}$. Given a common initial condition, this lowers the solution $\left[N_{t}^{*}, \Lambda_{t}^{*}\right]$. One implication would be that $\Lambda_{t}$ is higher in the ex ante steady state than in the $y_{t}=y_{\mathrm{L}}$ steady state. This contradicts Proposition 3.

To compare the ex ante equilibrium with the $y_{t}=y_{\mathrm{H}}$ ex post equilibrium, start with the solution for $\left(y, y_{\alpha}, y_{\beta}\right)=\left(y_{\mathrm{L}}, y_{\mathrm{H}}, y_{\mathrm{L}}\right)$, and then increase $y$ and $y_{\beta}$ to $y_{\mathrm{H}}$. Given a common initial condition, this raises the solution $\left[N_{t}^{*}, \Lambda_{t}^{*}\right]$. One implication would be that $\Lambda_{t}$ is higher in the $y_{t}=y_{\mathrm{H}}$ ex post steady state than in the ex ante steady state, again contradicting Proposition 3.

These contradictions imply that none of the stable manifolds can intersect as long as old projects are in use. Together with the fact that stable manifolds cross the $\mathrm{D} \Lambda_{t}=0$ curves from below, this implies that the stable manifolds are ranked as they are in the steady states.

\section{REFERENCES}

[1] Aghion, P. and G. Saint-Paul, "Virtues of Bad Times," Macroeconomic Dynamics, vol. 2 (1998), 322-344.

[2] Angeletos, G.-M. and J. La'O, "Sentiments," Econometrica, forthcoming (2012).

[3] Bai, Y., J.-V. Ríos-Rull, and K. Storesletten, "Demand Shocks as Productivity Shocks," working paper, University of Minnesota (2012).

[4] Bansal, R. and A. Yaron, "Risks for the Long Run: A Potential Resolution of Asset Pricing Puzzles" Journal of Finance, vol. 59, no. 4 (2004), 1481-1509.

[5] Barlevy, G. "The Sullying Effect of Recessions," Review of Economic Studies, vol. 69 (2002), 65-96.

[6] Barro, R.J., "Rare Disasters and Asset Markets in the Twentieth Century," Quarterly Journal of Economics, vol. 121, no. 3 (2006), 823-866.

[7] Beaudry, P. and F. Portier, "An Exploration into Pigou's Theory of Cycles," Journal of Monetary Economics, vol. 51 (2004), 1183-1216. 
[8] Blanchard, O.J. and P. Diamond, "The Cyclical Behavior of the Gross Flows of U.S. Workers," Brookings Papers on Economic Activity, vol. 1990, no. 2 (1990), 85-155.

[9] Caballero, R.J. and M.L. Hammour, "The Cleansing Effect of Recessions," American Economic Review, vol. 84, no. 5 (1994), 1350-1368.

[10] Caballero, R.J. and M.L. Hammour, "On the Timing and Efficiency of Creative Destruction," Quarterly Journal of Economics, vol. 111, no. 3 (1996), 805-852.

[11] Cochrane, J.H., "Shocks," Carnegie-Rochester Conference Series on Public Policy, vol. 41 (1994), 295-364.

[12] Cooper, R. and J. Haltiwanger, "The Aggregate Implications of Machine Replacement: Theory and Evidence," American Economic Review, vol. 83, no. 3 (1993), 360-382.

[13] Danthine, J.-P., J.B. Donaldson, and T. Johnson, "Productivity Growth, Consumer Confidence and the Business Cycle," European Economic Review, vol. 42 (1998), 1113-1140.

[14] Davis, S.J., J.C. Haltiwanger and S. Schuh, Job Creation and Destruction, MIT Press (1996).

[15] Den Haan, W.J. and G. Kaltenbrunner, "Anticipated Growth and Business Cycles in Matching Models," Journal of Monetary Economics, vol. 56 (2009), 309-327.

[16] Eaton, J. and S. Kortum, "Technology, Geography, and Trade," Econometrica, vol. 70, no. 5 (2002), 1741-1779.

[17] Hall, R.E., "Labor Demand, Labor Supply, and Employment Volatility," NBER Macroeconomics Annual, vol. 6 (1991), 17-47.

[18] Hopenhayn, H.A., "Entry, Exit, and firm Dynamics in Long Run Equilibrium," Econometrica, vol. 60, no. 5 (1992), 1127-1150.

[19] Hsieh, C.-T. and P.J. Klenow, "Misallocation and Manufacturing TFP in China and India," Quarterly Journal of Economics, vol. 124, no. 4 (2009), 1403-1448.

[20] Ilut, C. and M. Schneider, "Ambiguous Business Cycles," NBER working paper no. 17900 (2012). 
[21] Jaimovich, N. and S. Rebelo, "Can News about the Future Drive the Business Cycle," American Economic Review, vol. 99, no. 4 (2009), 1097-1118.

[22] Jaimovich, N. and H.E. Siu, "The Trend is the Cycle: Job Polarization and Jobless Recoveries," working paper, Duke University and University of British Columbia (2012).

[23] Lillien, D., "Sectoral Shifts and Cyclical Unemployment," Journal of Political Economy, vol. 90 (1982), 777-793.

[24] Lorenzoni, G., "A Theory of Demand Shocks," American Economic Review, vol. 99, no. 5 (2009), 2050-2084.

[25] Lucas, R.E., Jr. "Expectations and the Neutrality of Money," Journal of Economic Theory, vol. 4 (1972), 103-124.

[26] Lucas, R.E., Jr, "On the Mechanics of Economic Development," Journal of Monetary Economics, vol. 22 (1988), 3-42.

[27] Lucas, R.E., Jr. and E.C. Prescott, "Equilibrium Search and Unemployment," Journal of Economic Theory, vol. 7 (1974), 188-209.

[28] Luttmer, E.G.J., "Selection, Growth, and the Size Distribution of Firms," Quarterly Journal of Economics, vol. 122, no. 3 (2007), 1103-1144.

[29] Luttmer, E.G.J., "On the Mechanics of Firm Growth," Review of Economic Studies, vol. 78, no. 3 (2011a), 1042-1068.

[30] Luttmer, E.G.J., "Firm Growth and Unemployment," Federal Reserve Bank of Chicago seminar (2011b).

[31] Luttmer, E.G.J., "Growth with a Fixed Factor," Minnesota Economics Research Reports, no. 2012-01 (2012a).

[32] Luttmer, E.G.J., "Slow Convergence in Economies with Firm Heterogeneity," Federal Reserve Bank of Minneapolis working paper 696 (2012b).

[33] Melitz, M.J., "The Impact Of Trade On Intra-Industry Reallocations And Aggregate Industry Productivity," Econometrica, vol. 71, no. 6 (2003), 1695-1725. 
[34] Pastor, L. and P. Veronesi, "Learning in Financial Markets," Annual Review of Financial Economics, vol. 1 (2009), 361-381.

[35] Restuccia, D. and R. Rogerson, "Policy Distortions and Aggregate Productivity with Heterogeneous Plants," Review of Economic Dynamics, vol. 11 (2008), 707720 .

[36] Reinhart, C.M. and K.S. Rogoff, This Time is Different: Eight Centuries of Financial Folly, Princeton University Press (2009).

[37] Rogerson, R., "Sectoral Shocks, Human Capital, and Displaced Workers," Review of Economic Dynamics, vol. 8 (2005), 89-105.

[38] Santos, M.S. and M. Woodford, "Rational Asset Pricing Bubbles," Econometrica, vol. 65 , no. 1 (1997), 19-57.

[39] Scheinkman, J.A. and W. Xiong, "Overconfidence and Speculative Bubbles," Journal of Political Economy, vol. 111, no. 6 (2003), 1183-1219.

[40] Schmitt-Grohé, S. and M. Uribe, "What's News in Business Cycles," Econometrica, vol. 80 , no. 6 (2012), 2733-2764.

[41] Uzawa, H., "Optimum Technical Change in an Aggregative Model of Economic Growth," International Economic Review, vol. 6 (1965), 18-31.

[42] Zeira, J., "Informational Overshooting, Booms, and Crashes," Journal of Monetary Economics, vol. 43 (1999), 237-257. 